MARIA HELENA MATIKO AKAO LARSSON

\title{
ESTUDO EPIDEMIOLÓGICO DA BRUCELOSE CANINA
}

\author{
Tese apresentada ao \\ Departamento de Epidemiologia \\ da Faculdade de Saúde Pública da \\ Universidade de São Paulo, \\ para obtenção do título de Doutor.
}

Orientador: PROF. DR. RUY LAURENTI

SÃO PAULO

1979 
Aos meus pais

e irmão.

Ao Carlos Eduardo

e

Carlão. 
AGRADECIMENTOS.

Ao Prof.Dr. Ruy Laurenti, pela acolhida, amizade e orienta ção que sempre nos ofereceu.

Ao Prof.Dr. Leland E. Carmichael e ao Dr. Richard Poh1, pe 10 fornecimento, respectivamente, da amostra pa drão utilizada nas reações de soroaglutinação len ta e dos "kits" utilizados para execução das rea ções de soroaglutinação rápida.

A Profa.Dra. Elizabeth Oliveira da Costa Freitas Guimarães, pela orientação e auxílio no isolamento e identifí cação das amostras.

A Profa.Dra. Mitika K. Hagiwara, pelo estímulo,colaboração e sugestões apresentadas.

Aos Professores Dr. Eduardo Harry Birgel e Dr. Gil Vianna Paim, pela leitura cuidadosa do texto e valiosas sugestões.

A Profa.Dra. Masaio Mizuno Ishizuka, pela orientação e au xílio na tabulação e análise estatística dos resul tados obtidos.

Ao Prof.Dr. Omar Miguel, pela colaboração na anālise estạ tística dos resultados.

Ao Prof.Dr. Paulo Hideki Yassuda, pela cessão dos soros de cães errantes.

Ao Dr. Agnaldo Gonçalves, na qualidade de Diretor do Centro de Saūde "Geraldo de Paula Souza", da Faculdade de Saúde Pública da Universidade de São Paulo, pela cessão dos soros humanos.

A Sra. Regina Mieko Sakata Mirandola, pelo desmedido auxí lio na execução técnica deste trabalho.

Ao Sr. Nilson Eugênio Costa e ao acadêmico Moacir Kazuto Oizumi, pela colaboração prestada na coleta do ma terial. 
Ao Serviço Médico Cirúrgico e Hospitalar da Faculdade de Medicina Veterināria e Zootecnia da Universidade de São Paulo, pelas facilidades na obtenção e manu tenção dos animais inoculados.

As bibliotecārias Ana Maria Silveira Barone e Daisy Pires Noronha, bem como à Srta. Maria Inês Chareli, pela colaboração na obtenção, revisão e ordenação das referências bibliogrāficas.

Ao Sr. Sussumu Hagiwara, pelas ilustrações.

Aos colegas Gilberto De Grutolla e Plínio Rocha Campos,aos criadores Emerick Toaren e José Roberto Paiva e aos funcionários Altiva Lima Rodrigues e Francisco Vieira de Camargo, pela colaboração na realização deste trabalho. 
0 presente trabalho foi realizado visando o estudo da prevalência da infecção por Brucella canis em cães, através da pesquisa de anticorpos especificos, em dois grupos distintos de animais (de canil e errantes). Para tanto, foram utilizadas as provas de soroaglutinação rāpida (SAR) e soroaglutinação len ta $(\dot{S} A L)$. Nos animais soropositivos procurou-se, através de he mocultura, isolar o agente etiológico. Com o intuito de estudar a imunoresposta humoral e o período de bacteremia determinados por esse agente infeccioso, oito cães foram inoculados, por via oral, com uma amostra autóctone de Brucella canis (ES 11/78). Fi nalmente, para avaliar o risco da infecção humana por Brucella canis, examinaram-se trezentos e trinta soros humanos através da prova de SAL.

A prevalência da infecção nos animais de canil, se gundo a prova de SAR, foi de $9,1 \%$, enquanto que se obteve $2,4 \%$ de reagentes pela prova de SAL. Em relação aos animais errantes. observou-se $7,5 \%$ de reagentes pela prova de SAR e 7,0: pela pro va de SAL.

De seis animais reagentes examinados foram isoladas três amostras de Brucella canis: a amostra ES $11 / 78$, de um an mal de canil, e as amostras $215 / 79$ e $\operatorname{Pr} / 79$, de cães errantes. As referidas amostras foram identificadas através das característi cas morfológicas, tintoriais e bioquímicas e, sorologicamente, $\underline{u}$ tilizando antígenos produzidos com as mesmas.

Os animais inoculados experimentalmente, apresenta ram aglutininas, anti Brucella canis detectáveis, pela primeira vez, entre o $15^{\circ}$ e $35^{\circ}$ dias após a inoculação, segundo a prova de SAL, enquanto que a hemocultura foi positiva, pela primeira vez, 21 a 49 dias após a exposição dós cães ao agente infectante.

foi de $1,21 \%$.

A prevalência da infecção humana por Brucella canis 
The prevalency of canine brucellosis was determined in two distinct groups of animals, one from kennel dogs and the other one from stray dogs, through the detection of specific sc rum antibodies based on the results of tube agglutination test (TAT) and plate agglutination test (PAT). Attempts were made for the isolation of the infectious agent by means of blood culture of the seropositive animals. In order to study the humoral immu ne response and the period of bacteremia elicited by agent, eight dogs were experimentally infected, by oral route, with an autoch thon strain of Brucella canis (ES 11/78), isolated from one ken nel dog. The evaluation of human infection with Brucella canis was performed testing 330 serum samples.

The prevalence of the infection in the kennel dogs was 9.18 by plate PAT test and $2.4 \%$ by tube TAT test, while, in the stray dogs group, it was observed 7.58 of reagents by TAT and 7.08 of reagents by PAT.

Three samples of Brucella canis were isolated from the seropositive dogs: the strain ES 11/78, from a kennel dog, and strains $215 / 79$ and $\operatorname{Pr} / 79$ from stray dogs. The samples were identified through the morphological, staining and biochemical ca ractheristics of the agent as well as serological1y, using anti gens prepared with the isolated samples.

The experimentally infected dogs showed serum agglu tinins against Brucella canis, by the firt time, between the $15^{\text {th }}$ and $35^{\text {th }}$ days after inoculation, while the blood culture was po sitive, firstiy, 21 to 49 days after the exposition of the dogs to the infectious agent.

The prevalence of human infection with Brucella ca. nis was 1.218 . 
1. INTRODUÇAO $\ldots \ldots \ldots \ldots \ldots \ldots \ldots \ldots \ldots \ldots \ldots \ldots \ldots \ldots \ldots \ldots \ldots$

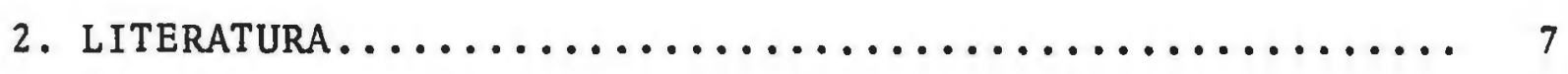

2.1. Prevalência da infecção em cães, segundo as provas de soroaglutinação rápida e soroaglutinação lenta e tipo de criação dos animais............... 7

2.2. Isolamento de Brucella canis............... 8

2.3. Inoculação experimental em cães: estudos bacterio lógico e sorológico...................... 10

2.4. Infecção por Brucella canis em humanos......... 10

3. MATERIAL E METODOS....................... 12

3.1. Prevalência da infecção em cães, segundo as provas de soroaglutinação rápida e soroaglutinação lenta e tipo de criação dos animais............... 12

3.2. Isolamento de Brucella canis.................. 15

3.3. Inoculação experimental em cães: estudos bacterio lógico e sorológico...................... 16

3.4. Infecção por Brucella canis em humanos......... 17

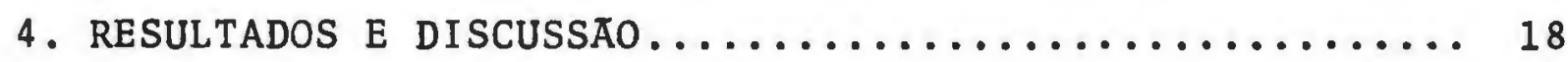

4.1. Prevalência da infecção em cães, segundo as provas de soroaglutinação rāpida e soroaglutinação lenta e tipo de criação dos animais............... 18

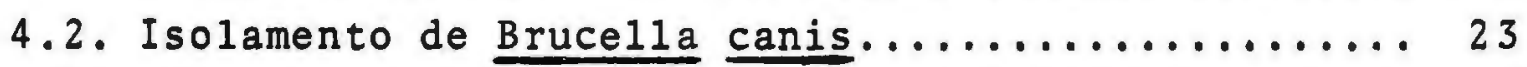

4.3. Inoculação experimental em cães: estudos bacterio lógico e sorológico...................... 25

4.4. Infeç̧ão por Brucella canis em humanos......... 38

5. CONCLUSOES............................ 41

6. REFERENCIAS BIBLIOGRAFICAS ................ 42 
1. INTRODUÇÃO . 
1. INTRODUCAO.

Brucella canis, agente de aborto canino, foi pri meiramente isolado em 1966 (CARMICHAEL ${ }^{11}$, 1967) e os primeiros trabalhos referentes à nova espécie de Brucella citam sua ocor rência epizoótica, principalmente em cães da raça Beagle (BRoWN e col., 7 1976). Os cães também podem ser acometidos por outras espécies de Brucella, como: Brucella abortus, Brucella suis ou Brucella melitensis. Tais infecçōes são de ocorrência esporádi ca e geralmente resultam do contacto de caẽs de zona rural com produtos de origem animal contaminados ou da ingestão de restos de aborto de origem brucélica (NICHOLETTI e col., ${ }^{50} 1967$; CLEGG 17,1968 ; PHILIPPON e col., 53 1969; ROBERTSON 57 , 1973).

A brucelose canina $\vec{e}$ uma doença contagiosa de cães que se caracteriza por aborto, infertilidade, comprometimen to de tecidos linfóides (MOORE ${ }^{44}, 1969$; SYMPOSIUM ON IMMUNITY... 67, 1970 ; SPINK 64,1970 ; SPINK \& MORISSET 65,$1970 ; \operatorname{MEYER} 43$, 1974) e bacteremia prolongada (SPINK ${ }^{64}, 1970$; VAN HOOSIER JR. e co1., 72 1970; CARMICHAEL \& GEORGE ${ }^{13}, 1976$ ).

Ao que tudo indica, o único animal em que a in fecção ocorre naturalmente é o cão (MOORE ${ }^{44}, 1969$; MOORE \& GU $\underline{p}$ TA ${ }^{46}, 1970$ ). Suinos, bovinos e ovinos são resistentes à infeç ção, por via oral, com Brucella canis, enquanto que os felinos podem ser infectados com o agente do aborto canino, por via oral (PICKERILL 54,1970$)$. Dentre os animais de 1aboratório, os ca mundongos, cobaios e coelhos são sensiveis à infecção por Brucella canis (MOORE 44,1969 ; MOORE \& GUPTA ${ }^{46}, 1970$ ).

A infecção acomete cães de todas as raças indife rentemente (MOORE ${ }^{44}$, 1969 ; LEWIS JR. ${ }^{37}, 1972$; CARMICHAEL $^{9}, 1976$ ) e a sua transmissão se dā por contacto com tecidos excretados ou com corrimento vaginal de fêmea que abortou recentemente, contac to com urina de animais infectados e acasalamento de macho infec tado com fêmea suscetível (MOORE ${ }^{44}, 1969$; ROBERTSON ${ }^{57}, 1973$; CAR 
MICHAEL \& GEORGE ${ }^{13}$, 1976). Cães recém-nascidos bacterêmicos in dicam a possibilidade de transmissão transplacentāria (VAN HOO SIER JR. e col. 72 , 1970).

A evidenciação clínica da brucelose canina tem sido descrita por värios autores (KIMBERLING e col. 36,1966 ; TAUL e col. ${ }^{68}, 1967$; MOORE ${ }^{44}, 1969$; MOORE \& KAKUK 47,1969 ; CARMI CHAEL \& KENNEY ${ }^{14}$, 1970 ; HILL e col. 32 , 1970; SPINK \& MORISSET 65 , 1970). O principal sinal é o aborto, que ocorre geralmente no decorrer do terço final da gestação $\left(48^{\circ}\right.$ ao $52^{\circ}$ dia) e é se guido de corrimento vaginal mais ou menos prolongado. Nos ma chos, os sinais consistentes da infecção são: epididimite, pros tatite, dermatite e/ou edema escrotal e, ocasionalmente, atrofia testicular, uni ou bilateral. Machos infectados manifestam-se relutantes ao acasalamento. Em ambos os sexos pode-se observar linfadenopatia, hépato e esplenomegalias.

Os achados patológicos da infecção por Brucella canis incluem uma hiperplasia marcante do tecido linfóide de to do organismo com proliferação de linfócitos, plasmócitos e cẻlu las reticulares. Em machos, observam-se ałterações da próstata, epidídimo e, ocasionalmente, de testículo (MOORE \& $\operatorname{KAKUK}^{47}, 1969$; CARMICHAEL \& KENNEY ${ }^{14}$, 1970; GLEISER e col. 26 , 1971 ; CARMICHAEL \& GEORGE ${ }^{13}$, 1976); em fêmeas, as únicas lesões significativas são os nôdulos de cêlulas reticulares no endométrio (SPINK \& MO RISSET ${ }^{65}$, 1970). Achados patológicos mais recentes incluem me ningoencefalite difusa (HARRIS.e col. 29 , 1974), espondilite (HEN DERSON e col. ${ }^{31}$, 1974) e uveite recurrente (RIECKE \& RHOADES 56 , 1975 ; SAEGUSA e col. 58,1977 ).

A ausência de pirexia em animais infectados e a natureza insidiosa da doença em fêmeas não prenhes dificultam o diagnóstico clínico do processo; entretanto, pode-se suspeitar de brucelose canina quando surgem abortos, nascidos-mortos, epi didimite ou atrofia testicular em machos sadios, insucessos repe tidos nos acasalamentos e linfadenopatia (MOORE \& GUPTA ${ }^{46}, 1970$; CARMICHAEL ${ }^{9}, 1976$ ). 
Os métodos sorológicos para diagnóstico da bruce lose canina compreendem a aglutinação lenta em tubo (CARMICHAEL 10, 1969; MOORE \& KAKUK 47,1969 ; SPINK \& MORISSET 65,1970 ; PI CKERILL \& CARMICHAEL 55 , 1972), aglutinação rāpida em placa(DAMP e col., 18 1973; GEORGE \& CARMICHAEL 24, 1974; BROWN e col., 1976; GEORGE \& CARMICHAEL ${ }^{25}, 1978$ ), fixação de complemento (P I CKERILL 54 , 1970; PICKERILL, 1970, e DEYOE, 1970, citados por CARMICHAEL 9 , 1976), ágar ge1-difusão (MYERS e col., ${ }^{49} 1974$; WE BER \& KRAUSS 79 , 1975) e imunofluorescência indireta (WEBER \& HUSSEIN ${ }^{78}, 1976$ ); entretanto, o diagnóstico definitivo deve ser baseado no isolamento do agente a partir de sangue (MOORE ${ }^{44}$, 1969; SPINK \& MORISSET ${ }^{65}, 1970$; SYMPOSIUM ON IMMUNITY $\ldots 67,1970$; PI CKERILL \& CARMICHAEL ${ }^{55}, 1972$ ), linfonodo ou medula óssea (CARMI CHAEL ${ }^{9}, 1976$ ).

Vários antibióticos têm sido utilizados no trata mento de animais infectados; porém, a bacteremia desaparece ape nas durante o tratamento, reaparecendo após o término do mesmo (MOORE ${ }^{44}, 1969$; LEWIS JR e col., 39 1973). JENNINGS e col. ${ }^{35}$ (1974) obtiveram sucesso limitado no tratamento de animais infectados utilizando combinações triplas de antibiōticos, em doses eleva das e por longos periodos. TERAKADO e col. ${ }^{69}$ (1978) verificaram uma grande suscetibilidade da Brucella canis à tetraciclina e aos antibióticos aminoglicosideos.

Segundo CARMICHAEL \& KENNEY ${ }^{14}$ (1970), o uso de vacina em cães é impraticâvel e inseguro, pois induz à infecção crônica e bacteremia.

Atualmente, o único controle efetivo da infecção em cães infectados è a identificação e a eliminação imediata dos mesmos. Estes devem ser identificados por métodos bacteriológi cos e sorológicos. A doença pode ser considerada erradicada de uma criação de cães quando todos os animais se apresentarem nega tivos em 3 exames sorológicos consecutivos. Preconiza-se a in trodução de animaịs novos numa criação quando estes apresentarem 2 exames de soroaglutinação lenta (SAL) negativos, com intervalo de 1 mês (MOORE \& GUPTA 46 , 1970; HALL ${ }^{28}, 1971$; PICKERILL \& CAR MICHAEL ${ }^{55}, 1972$; ROBERTSON ${ }^{57}, 1973$ ). 
O perigo da transmissão da brucelose canina ao homem tem sido abordado por FAIGEL ${ }^{19}$ (1969), FREEMAN ${ }^{22}$ (1971) e por WOOLEY e col. ${ }^{83}(1976)$. Apesar de que o único animal que tem apresentado infecção natural por Brucella canis seja o cão, a do ença tem potencial zoonótico devido à estreita relação daquele com o homem (LEWIS JR \& ANDERSON ${ }^{38}, 1973$ ), fato este que tem sido comprovado através dos relatos de casos humanos por Brucella canis (CARMICHAEL e co1. 1.5, 1968; SWENSON e co1. ${ }^{66}, 1972$; BLAN KENSHIP \& SANDFORD 4 , 1975; MUNFORD e col. ${ }^{48}$, 1975 ; LOVEJOY e col. ${ }^{40}$, 1976) e também através dos trabalhos de prevalência de anticorpos anti Brucel1a canis em soros humanos (LEWIS JR \& ANDER SON 38,1973 ; HOFF \& SCHNEIDER 34 , 1975; BARG e col. ${ }^{2}, 1977$; WE BER \& BRUNER 77,1977 ).

A doença no homem caracteriza-se por febre, tre mores, indisposição, perda de peso, linfadenopatia (CARMICHAEL e Col. ${ }^{15}, 1968$; SWENSON e col. ${ }^{66}, 1972$; BLANKENSHIP \& SANDFORD ${ }^{4}$, 1975; MUNFORD e col. ${ }^{48}, 1975$ ) e por hépato:e esplenomegalias (BLANKENSHIP \& SANDFORD 4,1975 ).

A brucelose canina tornou-se um problema de im portância em criações de cães nos Estados Unidos da América do Norte e, atualmente, hã evidências de que esta doença está aumen tando tambëm entre os homens. As infecçōes por Brucella canis pareciam estar restritas ao pessoal de laboratórin, não constí tuindo sềrio problema de Saúde Pública. Recentemente, entretan to, värios casos de infeç̧ão humana por Brucella canis têm sido descritos, inclusive aqueles relacionados com infecção em ani mais domiciliados (WOOLEY e col. ${ }^{83}, 1976$ ).

Considerando-se o risco a que pode estar sujeita uma população humana que, cada vez mais, vem mantendo contacto maior com cães, pretende-se, com o presente trabalho, fornecer alguma contribuição ao estudo da infecção por Brucella canis, vis to ser a literatura nacional muito escassa em relação ao assun to. Para tanto estabeleceram-se os seguintes objetivos: 
a) prevalência da infecção em cães, segundo as provaś de soroaglutinaçãu rápida (SAR) e soro aglutinaçāo lenta (SAL) e tipo de criação dos animais;

b) isolamento de Brucella canis dos animais rea gentes;

c) inoculação experimental em cães: estudos bac teriológico e sorológico;

d) infecçāo por Brucella canis em humanos.

Antes de se proceder ao item relativo ao mate rial e métodos, fêz-se uma revisão da literatura referente ao assunto no período de 1966 a 1978 . 
2. LITERATURA. 
2. LITERATURA.

2..1. Prevalência da infecção em cãcs, segundo as provas de so roaglutinação rápida c soroaglutinação lenta e tipo decria ção dos animais.

O diagnóstiço sorolögico da brucelose canina, rea lizado através do teste de aglutinação em tubo, apresenta certas limitações para ser usado rotineiramente em clíni cas (CARMICHAEL 10, 1969). As causas que limitam o seu emprego, de rotina, são as seguintes: a dificuldade de pro duzir antígeno devido à tendência da Brucella canis de se tornar viscosa após incubação prolongada, a natureza mu cóide do organismo que tem sido responsabilizada pela per da de aglutinaçāo completa de alguns soros de cāes infecta dos e a necessidade da mistura teste ser incubada a $50-52^{\circ} \mathrm{C}$ durante 48 horas (GEORGE \& CARMICHAEL 24,1974 ).

$\mathrm{Na}$ tentativa de sanar estas dificuldades, GEORGE \& CARMICHAEL 24 (1974) desenvolveram e avaliaram uma pro va de aglutinação rápida em placa para deteç̧ão de antí corpos anti Brucella canis, usando cultura de células mor tas e coradas de Brucella ovis, com base na identidade an tigênica entre as duas espécies de Brucella, e verificaram uma concordância total entre os resultados obtidos pelos dois métodos, ao examinarem 140 amostras séricas de cães infectados experimentalimente.

BROWN e col. ${ }^{8}$ (1976) realizaram inquérito soroló gico para pesquisa de aglutininas anti Brucella canis em populaçōes caninas errante e domiciliada, usando a soro aglutinaçāo rápida (SAR) como prova de triagem. Os reagen tes àquela prova foram reexaminados pela $\mathrm{SAL}$ e a avalia ção dos resultados indicou uma concordância de 99 entre ambos os testes, uma sensibilidade de 62,58 e uma especí ficidade de $99,7 \%$ para SAR: 
Em Minas Gerais, num estudo realizado com 2020 a mostras, pesquisou-se a presença de anticorpos anti Bru cella canis em soros humanos, pelo emprego das provas de SAL e SAR, e os resultados obtidos pelos dois métodos fo ram çoncordes (BARG e col., 2 1977).

WOOLEY e col. 84 (1977) verificaram sensibilidade de $100 \%$ e especificidade de $95,7 \%$ para a prova de SAR em relação à SAL ao pesquisarem aglutininas anti Brucella ca nis em soros de populạçōes caninas urbana e rural.

A infecção por Brucella canis foi inicialmente des crita numa criaçāo de Beagles, em Nova Jérsia, em 1966 , por CARMICHAEL 11 (1967). Desde então, värios pesquisado res diagnosticaram a doença em outros estados americanos (KIMBERLING e col., 36 1966; MOORE \& BENNET 45, 1967 ;TAUL e col., 68 1967; SPINK \& MORISSET 65 , 1970; HILL e col., 32 1970; HALL 28, 1971).

Os cães confinados em canis não são os únicos aco metidos pela Brucella canis; inquéritos sorológicos têm demonstrado também a prevalência desta infecçāo em ani mais errantes e domiciliados (FREDRICKSON \& BARTON 21 , 1974 ; UEDA e col., 71 1974; BROWN e col., 7 1976; HAYASHI \& ISAYAMA 30,1977 ; LOVEJOY e col., 40, 1976; SERIKAWA $\mathrm{C}$ col., 63 1977; WOOLEY e col., 84 1977; PEREIRA FILHO e col., 52 1978; WEBER \& SCHLIESSER ${ }^{81}, 1978$ ).

No Japão, a brucelose canina foi detectada pela primeira vez por YAMAUCHI e col. 85 (1974), em criação de Beagles, onde 16 machos e 116 fêmeas foram identificadós infectados, atravēs de hemocultura positiva ou título a glutinante igual ou maior a 400; seis meses depois, os re feridos autores conseguiram debelar a infeccão da criacão, atravẻs da eliminação dos animais infectados. Neste mes mo ano, UEDA e col. 70 (1974) detectaram aborto canino é pizoótico em outra colônia de Beagles em Shizuoka. Ainda no Japão, existem evidências da ocorrência de Brucelose canina, na área de Tokyo (UEDA e col., 71 1974; TERAKADO e col., 
69 1978), em Hokaido (HAYASHI \& ISAYAMA 30 , 1977), em Gi fu e Shiga (SERIKAWA e col., 63 1977) e em Kioto e Kana gawa (SERIKAWA e col., 62 1978).

Von KRUEDENER 74 (1974) fêz a primeira observa ção de brucelose canina em canil de Beagles, na Alemanha. Desde então, outros trabalhos têm confirmado a ocorrên cia desta infecção naqueie país (WEBER \& SCHLIESSER $80^{-}$, 1975 ; WEBER 76, 1976; WEBER \& SCHULZ 82, 1976; WEBER \& SCHLIESSER ${ }^{81}, 1978$ ). Outro país europeu em que a doen ça já foi diagnosticada è a Tchecoslováquia (SĚBEK é col., 61 1976).

Nas Amêricas existem evidências da infecção por Bruce 11a canis no México (FLORES-CASTRO \& SEGURA 20,1976) no Peru (ENGLEHARDT, 1974, citado por CARMICHAEL 9, 1976) e no Brasil (SANDOVAL e col., 591976 ; GODOY e col.,27 1977 e PEREIRA FILHO e col., 52 1978).

2.2. Isolamento de Bruce11a canis.

0 agente do aborto canino pertence $\vec{a}$ Ordem Eubacteriales Família Brucellacéae, Gênero Bruce11a, Esnćcie Brucella canis (BLAIR e col., 3 1970) e foi isolado, pela prime ra viez, de feto abortado (CARMICHAEL 11, 1967); desde en tão, a Bruce11a canis tem sido frequentemente incrimina da como causa de infertilidade em cães, em vārios locais do mundo.

Segundo CARMICHAEL ${ }^{10}$ (1969), os materiais de es colha para tentativa de isolamento de Brucella canis são: feto abortado, placenta, líquido alantóide, pulmão, fíga do, baço, linfonodo, corrimento vaginal de fêmea; isola mentos a partir de epidídimo e próstata não são frequen tes. 0 isolamento do agente a partir de sangue também é possível, sendo que o resultado de hemocultura positiva está relacionado comonível de antịcorpos circulantes. 
A maioria dos autores tem conseguido isolar Brucella canis de sangue periférico (CARMICHAEL e col., 15 1968; GLEISER e col 26. 1971; SWENSON e col.. 66 1972; YAMAUCHI e col., 85 1974; GODOY e col.. 27 1977).

MOORE \& KAKUK 47 (1.969), trabalhando com cães machos naturalmente infectados, não obtiveram sucesso em isolar Brucella canis de tecidos de nenhum animal nāo bacterêmico; por outro lado, conseguiram isolar o agente dos tecidos de cinco animais bacterêmicos. Urina obtida por punção vesical, em cinco casos, e próṣtata, em um caso, forneceram cultura positiva, sendo que um dos ani. mais apresentou cultura positiva em ambas amostras (uri na e próstata).

MCCORMICK e col. 42 (1970) conseguiram isolar Bruce 1la canis a partir de fetos abortados e sangue de uma cadela que abortara, recentemente. UEDA e col., 70 (1974) citaram o isolamento de Brucella canis a partir de baço, linfonodo, próstata e epidídimo em mais de 50 \% das amostras e de sangue, testículo e bexiga em $30-50 \%$ das amostras; ainda, conseguiram uma cultura positiva de medula óssea e de útéro nāo grāvido. HARRIs e col., 29 (1.974) relataram o isolamento de Brucella canis, em cade la Beagle com sintomatologia neurológica, a partir de $1 \underline{i}$ quido cefalorraquidiano.

Isolamentos menos frequentes foram aqueles obti dos por HENDERSON e col. 31 (1974) a partir do cultivo de fragmentos ósseos obtidos por biōpsia de lesōes de es pondilite, por RIECKE \& RHOADES 56 (1975) e SAEGUSA é col., 58 (1977) a partir de material ocular de casos de uveite e por SCHOEB \& MORTON ${ }^{60}$ (1978) a partir de lesão exsudativa de escroto. 
2.3. Inoculação experimental em cāes: estudos bacteriológico e sorológico.

Poucos são os trabalhos, referentes à inoculaçāo experimental em animais com Brucella canis, que constam da literatura.

JENNINGS e col. 35 (1974) e LEWIS JR e col. 39 (1973) procederam à inoculação experimental em cães com Brucella canis, com a finalidade de estudar o valor terapêutico de certos antibióticos como tetraciclina, ampicilina e es treptomicina.

Outro trabalho relativo à inoculação experimental de Brucella canis em cães foi aquele desenvolvido por SAE GUSA e col. 58 (1977), que observaram o aparecimento de lesões oculares (uveíte) recurrentes, no $217^{\circ}$ e $238^{\circ}$ dias após a inoculação, em 2 animais com infecção crônica. BROWN e col..$^{5}$ (1975) realizaram inoculação experimentalde Brucella canis em cães com o propósito de estudar o desen volvimento de aglutininas anti Brucella canis e o apareci mento de bacteremia.

Segundo PERCY e col. 51 (1972), quatro símios (Ma caca arctoides) inoculados com cultura de Brucella canis reproduziram a doença, confirmada sorologicamente e bac teriologicamente, com reisolamento do agente, a partir de sangue e tecidos.

2.4. Infecção por Brucella canis em humanos.

Atualmente não há dúvidas de que o agente do abor to canino pode acometer o homem, quer acidentalmente por condições de trabalho (CARMICHAEL e col., ${ }^{15}$ 1968), quer em decorréncia do contacto com cães infectados (SWENSON e co1., 66 1972; BLANKENSHIP \& SANDFORD ${ }^{4}, 1975$; MUNFORD e col., 48 1975; LOVEJOY e col., 40 1976). 
Os inquéritos sorológicos para pesquisa de aglutí ninas anti Brucella canis em humanos têm comprovado, tạ bém, a suscetibilidade do homem a este agente (LEWIS JR $\varepsilon_{\text {}}$ ANDERSON 38 , 1973 ; HOFF \& SCHNEIDER ${ }^{34}$, 1975 ; BARC c col., 2 1977; WEBER \& BRUNLR 77, 1977). 
3. MATERIAL E METODOS.

BIBLIUTELA

PACULDADE DE SAUDE PUBLIC.

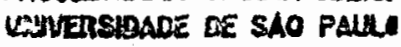


3. MATERIAL E METODOS.

Para o isolamento, preparo de antigeno e manuten çāo das culturas, utilizaran-se os seguintes meios: Brucella - á gar" e Brucella-broth"

Para a execuçāo da prova de SAR, utilizou-se o "kit" "Canine Brucellosis Diagnostic Test"". 0 antígeno para rea lizaçāo da prova de SAL foi preparado a partir de Brucella canis (RM 6-66) e o controle das partidas de antígeno foi feito uti. lizando-se anti-soro"*". preparado em cão.

Para a avaliação estatística dos resultados, uti lizaran-se: o cálculo do coeficiente de associaçāo de Yule e o câlculo de mediana (MARASCUILlo ${ }^{41}, 1971$ ).

3.1. Prevalência da infecção em cāes. segundo as provas de sọ roaglutinação rápida e soroaglutinaçāo lenta e tipo de criaçāo dos aniąais.

Exaninaram-se trezentos e sessenta e quatro so ros de cāes adultos, sea distinçāo de sexo e raça, sendo cento e sessenta e quatro procedentes de canis e duzen tos errantes . Os canis, cujos aninais foram incluí

\footnotetext{
* Difco.

** Gentilente cedido pela Pitman-Moore, através do Senhor Doutor Richard Pohl da Johnson \& Johnson, Säo Paulo, Bra sil.

t** Gentilente cedidos pelo Professor Doutor Leland E. Carni chael da Universidade de Cornell, Ithaca, Hova Iorque, E. U.A.

th* Gentilnente cedidos pelo Doutor Paulo Hideki Yassuda do Instituto de Ciências Biomédicas da Oniversidade de são Paulo.
} 
dos nesta pesquisa, eram constituidos por 4-50 animais. Destes eram coletadas amostras de $5 \mathrm{~m} 1$ de sangue da veia jugular direita e/ou esquerda, seguindo-se os devidos cuidados de assepsia e, imediatamente, centrifugadas a 3.000 r.p.m., durante 15 minutos, para separaçāo e obten ção dos soros. Foram utilizados somente os soros não he molisados, que eram estocados a $-20^{\circ} \mathrm{C}$, atè o momento da realização das provas sorológicas.

Utilizou-se, no presente trabalho, o Teste Diag nóstico para Brucelose Canina (Pitman-Moore) para a rea lização da prova de SAR.

o procedimento para execuçāo da referida prova foi o.seguinte:

a) sôbre uma lâmina de vidro, colocavam-se 1 gota de so ro problema numa extremidade e 1 gota de anti- soro (controle positivo) noutra extremidade;

b) adicionava-se uma gota de antígeno corado a cada uma das gotas de soro; homogeneizava-se cada mistura antí geno-soro com um bastão aplicador, espalhando-a numa ärea circular de aproximadamente $2 \mathrm{~cm}$ de diâmetro;

c) a leitura da prova era feita dentro de 2 minutos, agi tando-se a lâmina lenta e cuidadosamente;

d) consideravam-se positivas as misturas antígeno- soro que aglutinassem em 2 minutos; por outro lado, consi deravam-se negativas aquelas que não aglutinassem no mesmo tempo de observação.

- A prova de soroaglutinação lenta foi realizada segundo a técnica precónizada por CARMICHAEL (1976) , obe

* Informação pessoal de L.E. Carmichael do Cornell Research Laboratory for Diseases of Dogs, Ithaca, N.Y. -Standard tube agglutination test protocol for Brucella canis diagnosis, 1976. 
decendo as recomendações descritas a seguir.

Preparação de antígeno: o antígeno para mêtodo lento era preparado a partir de culturas de Brucella canis (RM 6-66), com 48-72 horas de crescimento, em garrafas de Roux contendo Brucella-âgar. As colônias de bactêrias eram removidas com a adição de $25 \mathrm{ml}$ de solução tamponada (pH $7,2$ e $0,15 \mathrm{M})$. A suspensão resultante era filtrada, atra vês de seis camadas de gaze, e lavada duas vezes com a referida solução tamponada, por meio de centrifugação a 10.000 r.p.m., durante 20 minutos. Após a segunda 1ava gem, o sedimento era ressuspenso em aproximadamente 10 m1 da citada solução tamponada e mantido em banho-maria, a $60-62{ }^{\circ} \mathrm{C}$ durante 2 horas, obtendo-se, desta forma, ant $\underline{i}$ geno morto. Para evitar contaminação, adicionava-se Mer thiolate $0,01 \%$. O antígeno concentrado, assim obtido, era armazenado a $4{ }^{\circ} \mathrm{C}$, até o momento do uso. Para a rea lização da prova, o antígeno era diluído à densidade óp tica de 0,2 , em comprimento de onda de $420 \mathrm{~nm}$, em espec tofotômetro Coleman Jr. II, modelo $6 / 20$.

o procedimento para execução da prova de soroa glutinação lenta foi o seguinte:

a) uma bateria de tubos de ensaio 12 x $75 \mathrm{~mm}$ eram numera dos de 1 a 7 ;

b) com uma pipeta de $0,1 \mathrm{~m} 1$, colocavam-se 0,04, 0,02, 0,01 e $0,005 \mathrm{~m} 1$ de soro, respectivamente, nos tubos 1 , 2,3 e 4 . A seguir, preparava-se uma solução diluída de soro (1:10), em solução tamponada ( $\mathrm{pH} 7,2$ e $0,15 \mathrm{M})$ que era colocada nas quantidades de $0,08,0,04$ e $0,02 \mathrm{ml}$, respectivamente, nos tubos 5,6 e 7 ;

c) para obtenção das diluições $1: 50,1: 100,1: 200,1: 250$, $1: 400$, 1:500 e 1:1.000, adicionavam-se, a cada tubo, $2 \mathrm{~m} 1$ de antígeno diluído; a seguir, os tubos eram incu bados, em estufa a $50-52^{\circ} \mathrm{C}$, durante 48 horas; 
d) finalizando, realizavam-se duas 1eituras: uma após 24 horas de incubação e a segunda após 48 horas de incu bação. Os resultados eram avaliados comparando-se o grau de turvação das reações nos tubos transparentes, contendo soro desconhecido e aquele contendo soro con trole. Consideravam-se positivos os soros, em cujos tubos não havia reação com turvação, indicando agluti nação e formação de complexo antígeno-anticorpo, que se precipitava no fundo dos tubos; consideravam- se negativos os soros em cujos tubos permaneciam reações com turvação, após 48 horas de incubação;

e) consideravam-se positivos os soros que apresentassem ag̣utinação em diluições iguais ou maiores a 100 .

3.2. Isolamento de Brucella canis.

As tentativas de isolamento de Brucella canis fo ram feitas em cães confinados e em animais errantes, uti lizando-se dezessete animais adultos, sem distinção de sexo e raça, pertencentes a um mesmo canil com histōria passada de infertilidade, assim como dez animais erran tes. Coletava-se de cada animal uma amostrá de $2 \mathrm{ml}$ de sangue, destinada à realização de hemocultura.

Hemocultura: para comprovação de bacteremia e isolamen to do agente utilizando amostras sanguíneas, coletavam -se, assepticamente, $2 \mathrm{ml}$ de sangue da veia jugular di reita e/ou esquerda. Imediatamente, o material era co locado em tubos, contendo $5 \mathrm{ml}$ de Brucella-broth, com ci trato de sódio a $0,1 \%$, e incubado a $37^{\circ} \mathrm{C}$ durante 5 dias. Após este período de incubação, em meio específico, o ma terial era semeado em placas de Brucella-ágar e incubado a $37^{\circ} \mathrm{C}$. O crescimento de colônias de Brucella canis era observado após 48-72 horas de incubação. A seguir, pro cedia-se ao exame das características morfológicas e bio químicas do agente. 
$\mathrm{Na}$ determinação das características morfológicas consideraram-se: a forma do mircrorganismo, as caracterís ticas tintoriais pela coloração de Gram, a forma e o as pecto das colônias e o tempo de incubação para crescimento das mesmas.

As características bioquímicas foram avaliadas me diante as seguintes provas: catalase, oxidação e fermenta ção no meio de Hughes-Leifson, motilidade em ágar semisó lido, glicose e acidificação e hidrōlise da uréia, provas estas utilizadas, comumente, para caracterização do gêne ro Brucella. (BLAIR e col., ${ }^{3} 1970$ ). Para identificação da espécie Brucella canis utilizaram-se, ainda, a prova de produção. de $\mathrm{H}_{2} \mathrm{~S}$ e a verificação de crescimento de colônias, em presença de diferentes concentraçōes de corantes (tion na e fucsina).

3.3. Inoculação experimental em cães: estudos bacteriológico e sorológico.

Para a inoculação experimental, utilizaram-se oito animais adultos, três fêmeas e cinco machos, sem raça de finida, selecionados através exames clínico e laboratorial (hemograma e exame de urina), não reagentes para as pro vas de SAR e SAL e com hemocultura negativa para Bruce11a canis. Os animais foram identificados pelos números: 201, $203,206,209,214,216,218$ e 219. Antes de serem in cluídos no experimento, foram imunizados contra Cinomose e Hepatite Infecciosa Canina e receberam, também, tratamen to anti-helmíntico (Mebendazole, na dose de $30 \mathrm{mg} / \mathrm{kg} / \mathrm{dia}$, durante 3 dias). Assim preparados, os animais foram man tidos isọlados e em observação por 30 dias. Após es te período de isolamento, os caẽs foram examinados, nova mente, por meio de provas sorológicas e, então, inocu lados com uma suspensão de Brucella canis (ES 11/78), isolada no presente trabalho. Esta foi preparada à 
semelhança do antígeno para SAL; todavia, deve-se desta car que este inóculo não foi aquecido a $60-62^{\circ} \mathrm{C}$, bem co mo não recebeu adição de Merthiolate. A suspensão con centrada da citada amostra foi diluída, segundo o tubo 3 da Escala de McFarland, sendo inoculada, nos animais des te grupo experimental, na dose de $1 \mathrm{ml}$ por via oral.

A partir de um tempo zero, correspondente à data da inoculação, os cães foram sangrados, a intervalos de 7 dias, até a ocasião do sacrifício, para a realização das provas sorológicas, já descritas no ítem $3.1 ., \mathrm{e}$ he mocultura descrita no item 3.2. Nas duas primeiras cole tas, colheu-se material apenas para a execução das pro vas sorológicas; a partir da 3a. coleta, obtinha-se san gue para separação de soro, destinado às provas sorológi cas, assim como para hemocultura.

Os cães de números 206, 209, 216 e 218 foram ob servados durante 49 dias; os quatro animais restantes, is to é, os de números $201,203,214$ e 219 foram mantidos por mais 42 dias, totalizando 91 dias de observação a pós a inoculação.

3.4. Infecção por Bruce1la canis em humanos.

Trezentos e trinta soros humanos * foram examina dos para pesquisa de aglutininas anti Brucella canis. Os soros foram mantidos a $-20^{\circ} \mathrm{C}$ até o momento da execução da prova de SAL, descrita no item 3.1., utilizando-se a penas aqueles em evidência de hemólise.

* Gentilmente cedidos pelo Laboratório Clínico do Centro de Saú de "Geraldo de Paula Souza" da Faculdade de Saúde Püblica da Universidade de São Paulo. 
4. RESUltado E DISCUSSAO. 
4. RESULTADO E DISCUSSAO.

4.1. Prevalência da infecção em cães, segundo as provas de so roaglutinação rāpida e soroaglutinação lenta c tipo de criação dos animais.

Conforme se visualiza na TABELA $N^{\circ} 1$ observou-se, no presente trabalho, segundo a prova de SAR, uma prevalência de 15 reagentes $(9,1 \%)$ entre os animais de canil e de 15 reagentes $(7,5 \%)$ entre os animais de rua. Segundo a prova de SAL, a prevalência observada foi de 4 positivos $(2,4 \%)$ em relação aos animais de canil e de 14 positivos $(7,0 \%)$ para os animais errantes.

TABELA Nọ 1 - Animais da espécie canina, segundo resulta dos das provas de SAR e SAL para Brucella canis, e tipo de criação. São Paulo, 1979 .

\begin{tabular}{|c|c|c|c|c|c|c|c|c|c|c|}
\hline Provas & \multicolumn{4}{|c|}{$\mathrm{S} A \mathrm{R}$} & & \multicolumn{4}{|c|}{$S$ A L } & \multirow{3}{*}{ Tota } \\
\hline \multirow{2}{*}{$\begin{array}{l}\text { Tipo Resul } \\
\text { de } \text { ta }^{-} \\
\text {criação dos }\end{array}$} & \multicolumn{2}{|c|}{ Positivos } & \multicolumn{2}{|c|}{ Negativos } & 1000 & \multicolumn{2}{|c|}{ Positivos } & \multicolumn{2}{|c|}{ Negativos } & \\
\hline & Freq. & $\%$ & Freq & . $\%$ & & Freq & . $\%$ & Freq & $\%$ & \\
\hline CANIL & 15 & 9,1 & 149 & 90,9 & 164 & & 2,4 & 160 & 97,6 & 164 \\
\hline ERRANTE & 15 & 7,5 & 185 & 92,5 & 200 & 14 & 7,0 & 186 & 93,0 & 200 \\
\hline
\end{tabular}

GALPHIN JR. 23 (1977), realizando um inquérito sorológico para pesquisa de anticorpos anti Brucella ca nis, obteve seis reagentes pela prova de SAR, dos quais apenas um foi positivo pela prova de SAL. A semelhança do que observou o citado autor, os resultados obtidos no presente trabalho, relativos à comparação entre as pro vas de SAR e SAL, permitem reconhecer a prova de SAR co mo um teste bastante específico para pesquisa de anticor pos anti Brucella canis, porém, que pode fornecer resul tados falso-positivos. 
Por outro lado, resultados referentes à concor dância entre as provas de SAR e SAL foram observados por vários autores (DAMP e col. 18, 1973; GEORGE E CARMICHA $\mathrm{EL}^{24}, 1974$; BROWN e col. ${ }^{8}, 1976$; WOOLEY e co1. ${ }^{84}$, 1977). Assim, ao examinarem soros humanos e de cães por meio das provas de SAR e SAL para pesquisa de aglutininas an ti Brucella canis, DAMP e col. ${ }^{18}$ (1973) verificaram que - teste de microaglutinação em placa produz resultados semelhantes àqueles obtidos pelo método padrão, concluin do, ainda, que aquele método constitui um meio econômico de triagem para este tipo de avaliação. GEURGE E CARMI CHAEL 24 (1974) desenvolveram e avaliaram um teste de a glutinação rápida em placa, para detecção de anticorpos anti Brucella canis, usando células mortas e coradas de Brucella ovis, o que é possível devido à identidade anti gênica entre ambas espécies de Brucella. Num estudo que abrangeu um total de 140 amostras de soros examinadas, os autores obtiveram uma concordância de resultados en tre os dois testes, isto é, SAR e SAL.

BROWN e col. ${ }^{8}$ (1976), realizaram um inquérito sorológico, para pesquisa de anticorpos anti Brucella ca $\underline{\text { nis, }}$ em populações caninas errante e domiciliada, me diante a prova de SAR, sendo que os animais reagentes pa ra esta prova foram, reexaminados pela SAL, e verificaram uma concordância de $99 \%$ entre ambos os testes. A reava liação dos dados obtidos pelos autores indicou que a pró va de SAR apresenta uma sensibilidade de $62,5 \%$ e uma es pecificidade de $99,7 \%$ quando comparada à SAL.

WOOLEY e col. ${ }^{84}$ (1977) realizaram um inquérí to sorológico em populações caninas rural e urbana da Ge órgia, utilizando as provas de SAR e SAL para detecçãode aglutininas anti Brucella canis, e verificaram, ao compa rar ambos os testes, que a prova de SAR apresenta sensi bilidade de $100 \%$ e especificidade de $95,7 \%$ em relação à SAL. Os resultados obtidos por BROWN e col. ${ }^{8}$ (1976) e por WOOLEY e col. ${ }^{84}$ (1977), relativos à sensibilidade e especificidade do teste de SAR, caracterizam esta prova 
como um bom meio de triagem para pesquisa de anticorpos anti Brucella canis em amostras séricas.

Posteriormente, pretende-se realizar um estudo comparativo entre as provas de SAR c SAL, com a finalida de de avaliar a sensibilidade e a especificidade da pri meira em relação à segunda.

Existem também trabalhos referentes à compara ção de outros testes como ägar-precipitação (WEBER \& KRAUSS $^{79}$, 1975) e gel-difusão em lâminas (MYERS e col., 49 1974 ) com a prova de SAL. De um modo geral, os resulta dos obtidos por aqueles testes são comparáveis aos obti dos pela prova de SAL, o que os faz indicar como uma prova suplementar à da SAL.

Segundo a prova de SAL, a mediana do título de anticorposfoi 100 em relação aos animais criados em sis tema de canil, enquanto que para os cães de rua o valor foi 250 , como se observa, respectivamente, nas TABELAS N: 2 e N: 3 .

TABELA No 2 - Frequência dos títulos de anticorpos anti Brucella canis, em animais criados em cá nis, segưndo a prova de SAL. Säo Paulo, 1979.

\begin{tabular}{c|c}
\hline Título & Frequência \\
\hline 100 & 2 \\
200 & 1 \\
250 & - \\
400 & - \\
500 & - \\
1000 & 1 \\
\hline
\end{tabular}


TABELA No 3 - Frequência dos tîtulos de anticorpos anti Brucella canis em cães errantes, segundo a prova de SAL. São Paulo, 1979

\begin{tabular}{c|c}
\hline Título & Frequência \\
\hline 100 & 3 \\
200 & 3 \\
250 & 2 \\
400 & 1 \\
500 & 1 \\
1000 & 4 \\
\hline
\end{tabular}

HOFF \& NICHOLS 33 (1974); na Flórida, realizan do um inquérito sorológico envolvendo 247 animais de ca nil, obtiveram uma porcentagem de soropositividade igual a 3,65 , através da prova de $S A L$, resultado bastante s melhante ao obtido no presente trabalho.

Outros trabalhos atinentes à prevalência da bru celose canina em animais confinados em canil fornecem re sultados que variam de $10,3 \%$ a $43,3 \%$. Von KRUEDENER $7 . \overline{5}$ (1976), na Alemanha,..examinando 200 soros de cães de uma criação de Beagles, obteve uma prevalência de $39 \%$ de rea gentes, considerando título positivo igual ou maior a 400. Por outro 1 ado, WEBER ${ }^{76}$ (1976) e WEBER \& SCHULZ 82 (1976) examinando 1190 e 650 soros, respectivamente, en contraram as seguintes porcentagens de soropositivos:10,3 e 10,5 , com títulos variando de 50 a 600 . SEBEK e col. 61 (1976), na Tchecoslovāquia, obtiveram uma prevalência de $43,3 \%$ de reagentes para Bruce1la canis de um total de 171 animais examinados.

No referente aos animais errantes, encontrou-se, no presente trabalho, uma prevalência de anticorpos anti Brucella canis igual a $7,5 \%$ (15 reagentes), através da prova de SAR, e igual a $7 \%$ (14 reagentes), através da prova de SAL. Estes resultados estão concordes com aque 
les de: FREDRICKSON \& BARTON 21 (1974) que obtiveram uma prevalência de $6,6 \%$ de brucelose canina entre animais ex rantes, no Tenessi, considerando titulo igual ou maior a 200 como indicativo de infeç̧ão: BROWN e col. 8 (1976), que de um total de 100 amostras séricas de cães errantes, observaram $9(9 \%)$ com título igual ou maior a $100 ;$ de WOOLEY e col. 84 (1977) que também obtiveram $9 \%$ de soro positivos, pela prova de $S A L$, em população canina urbana errante. Resultados de prevalência bem mais baixa foram encontrados por UEDA e col. 71 (1974) e SANDOVAL e col. 59 (1976) que observaram, respectivamente, $3,65 \%$ e $3,61 \%$ de animais reagentes para Brucella canis. Apesar de não fornecer a porcentagem de prevalência encontrada, LOVEJOY e col. 40 (1976) citaram que a totalidade dos animais po sitivos pertencia à população de cães errantes.

Os trabalhos relativos à prevalência de bruce lose canina na população de animais domiciliados mostram dados que variam de 1 a $2,9 \%$ (BROWN e col., 1976 ;SERIKA WA e col., 63 1977; PEREIRA FILHO e col., 52 1978; WE BER \& SCHLIESSER 81 , 1978), através do teste de SAL, con siderando titulo igual ou maior a 100 .

$\mathrm{Na}$ presente pesquisa, os canis, cujos animais foram examinados, eram constituídos por 4-50 cães apre sentando, assim, um caräter mais domiciliar do que de criação, sendo, portanto, mais fácil detectar e contro lar qualquer tipo de infecção. Este fato pode ser a jus tificativa da baixa prevalência da infecção relativa aos cães de canil, encontrada no presente trabalho, assim co mo a mediana do título de anticorpos mais baixa neste gru po de animais quando comparada à dos cães de rua. 
4.2. Isolamento de Brucella canis.

Dezessete animais adultos, sem distinção de se xo e raça, pertencentes a um mesmo canil com anteceden tes de infertilidade, foram examinados, por 3 ocasiōes, para deteç̧ão de anticorpos anti Brucella canis, atra vés das provas de SAR e SAL, assim como por meio de he mocultura, para tentativa de isolamento do agente a par tir de sangue. Na terceira tentativa, obteve-se resul tado positivo de um animal.

Ao realizar a seleção dos animais para inocu lação experimental, encontraram-se dois, portadores de altos niveis de aglutininas anti Brucella canis circu lantes. Diante de tais achados, procedeu-se à coleta de sangue para hemocultura e esta foi positiva para am bos.

0 agente etiológico isolado dos três animais tratava-se de um cocobacilo, Gram negativo; as colônias apresentavam-se pequenas, circulares, de coloração bran co grisáceo, cremosas e cresciam após 48 horas de incuba ção. O crescimento bacteriano tornava-se mucóide após 5 - 7 dias de incubação.

A identificação bioquímica dos agentes isola dos dos três animais foi a seguinte: catalase ${ }^{+}$, oxida ção e fermentação-, motilidade-, glicose e acidifica ção-, uréiat, produção de $\mathrm{H}_{2} \mathrm{~S}+$ (em 6 dias). 0 crescí mento de colónias, em presença de diferentes concentra ções de corantes, comportou-se da seguinte forma:

$$
\begin{aligned}
\text { tionina } & 1: 25.000:+ \\
1: 50.000:+ & \text { fucsina } 1: 50.000:- \\
1: 100.000:+ & 1: 100.000:+
\end{aligned}
$$

As amostras isoladas dos 3 animais apresenta ram as mesmas características morfológicas e bioquími cas, quando comparadas à amostra padrão (RM6-66). 
As cepas isoladas foram liofilizadas e enviadas para $\underline{i}$ dentificação e tipificação. A primeira cepa isolada,de animal de canil, foi enviada ao Prof. Dr. Leland E. Car michael que confirmou nossas observações e o isolado foi denominado Brucella canis (ES 11/78). As outras duas cepas isoladas foram enviadas ao Centro Panamericano de Zoonoses e receberam as respectivas denominaçōes de Bru ce11a canis $(\operatorname{Pr} / 79)$ e Bruce11a canis (215/79).

Por meio de hemocultura, foram isoladas trēs amostras de Bruce11a canis: (ES 11/78), Bruce11a canis (Pr/79) e Brucella canis (215/79) que apresentaram as mesmas características morfológicas e bioquímicas da amostra padrão (RM6-66); os animais, dos quais foram ob tidos os isolamentos, eram portadores de títulos agluti nantes iguais ou maiores a 400 . Estas observações são semelhantes às de GLEISER e col. 26 (1971) e às de Ya MAUCHI e col. 85 (1974), que obtiveram, também, hemocu1 tura positiva de animais com títulos iguais ou maiores a 400 . GODOY e col. 27 (1977) encontraram um animal com título aglutinante igual a 200 e que também forne ceu hemocultura positiva.

O agente etiológico do aborto canino apresenta características morfólógicas e bioquímicas, jā descrí tas anteriormente, que são utilizadas para sua identifi cação. Entretanto, entre uma amostra e outra podem ocorrer pequenas variações, como produção lenta de $\mathrm{H}_{2} \mathrm{~S}$ (CARMICHAEL e BRUNER ${ }^{12}$, 1968; MCCORMICK e co1., 421970) e crescimento em pequenas concentrações de fucsina (SWEN SON e col., 66 1972; VERGER e col., 73 1975).

Segundo ALTON e col. 1 (1976), Brucella canis não produz $\mathrm{H}_{2} \mathrm{~S}$ (em 4 dias), enquanto que CARMICHAEL 10 (1969) cita a produção de $\mathrm{H}_{2} \mathrm{~S}$ em 6 - 7 dias; relativa mente ao crescimento de colónias em diferentes concen trações de corantes, tanto ALTON e col. ${ }^{1}$ (1976) como CARMICHAEL ${ }^{10}$ (1969) consideram crescimento favorável de Brucella canis em presença de qualquer concentração de 
tionina e crescimento negativo em presença de fucsina na concentração de 1:50.000; entretanto, no referente ao crescimento de Brucella canis, em presença de fucsina, na concentração de 1:100.000, ALTON e col. ${ }^{1}$ (1976) conside ram negativo ou positivo, ao passo que CARMICHAEL ${ }^{10}$ (1969) considera crescimento positivo.

4.3. Inoculação experimental em cã̉es: estudos bacteriológico e sorológico:

Dos oito animais inoculados experimentalmente,com Brucella canis (ES 11/78), isolada no presente trabalho, sete demonstraram sinais de infecção, que foi comprovada atravês de provas sorológicas, isto é, provas de SAR e SAL, assim como por meio de hemocultura positiva.

Os resultados relativos à prova de SAL e hemocul cura foram apresentados sob a forma de gráfico, para ca da animal, individualmente, com exceção daquele que não apresentou evidências bacteriológicas ou sorológicas da infeç̧ão. (animal $n^{\circ}$ 201). (GRAFICOS $N^{\circ} 1$ a $N^{\circ}$ 7). Ain da, para uma melhor visualização dos resultados obtidos, f́êz-se uma tabela em que são computados os resultados, de todos os animais, relativos à prova de SAL e hemocultura, no decorrer de todo o experimento. (TABELA $N^{8} 4$ ). 


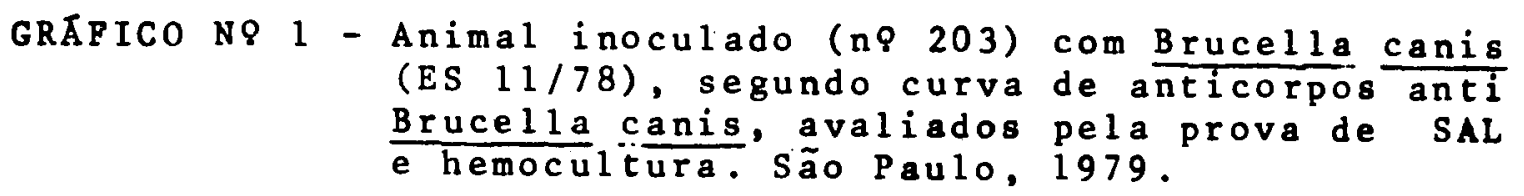

Titulo de
anticorpos

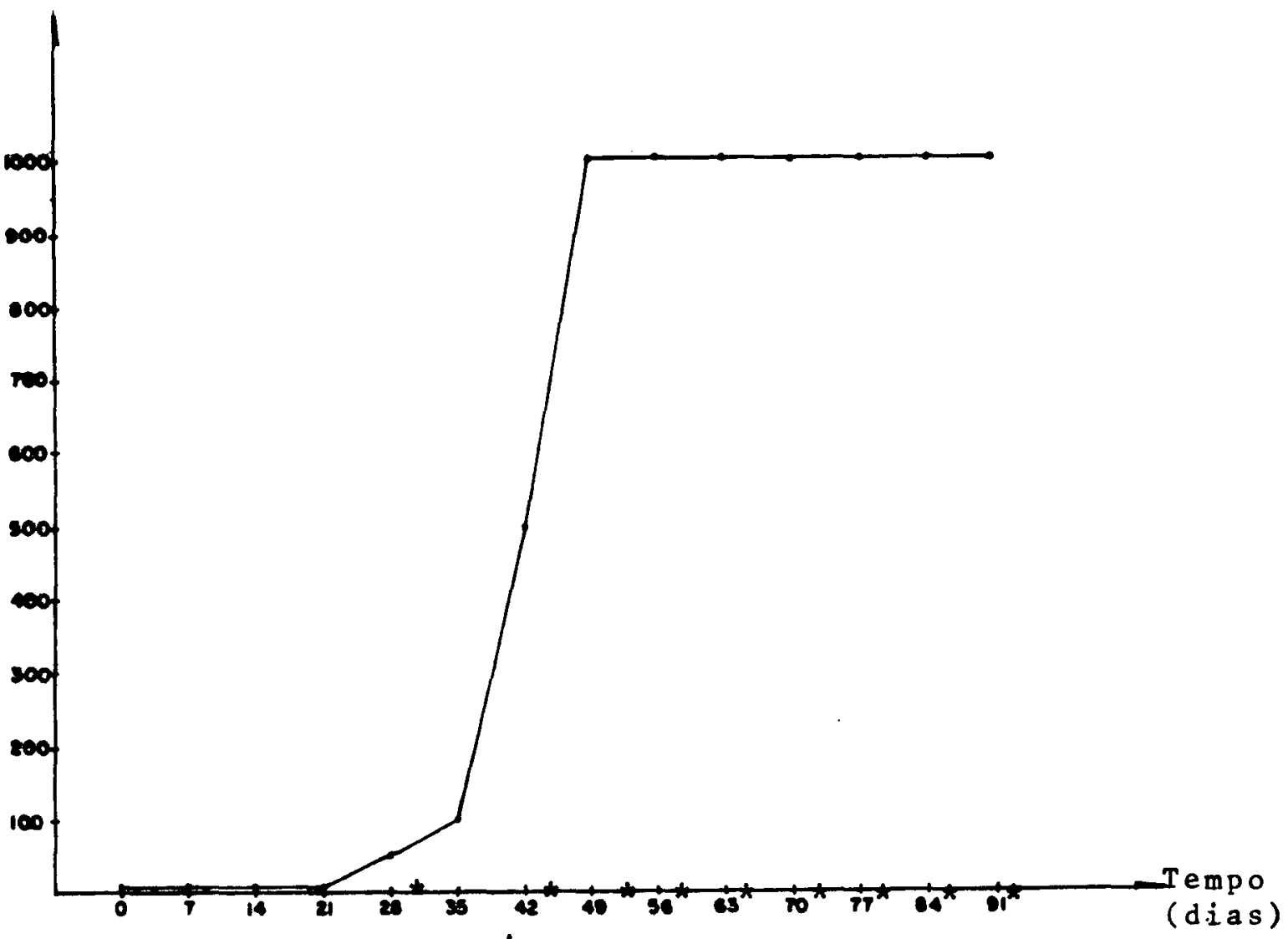

* Hemocultura positiva.

0 animal no 203 começou a apresentar anticorpos circulan tes a partir do 289 dia após a inoculação, elevando, gradat $\vec{i}$ vamente, os níveis até atingir título 1.000 no 49 o dia de ob servação. Título este mantido até o final do período de ob servação de 91 dias.

No 289 dia após a inoculação, embora portador de um títu 10 de anticorpos, relativamente baixo, o animal 203 apreseñ tou hemocultura positiva, que negativou na coleta seguinte , voltando a positivar nas oito coletas subsequentes. 


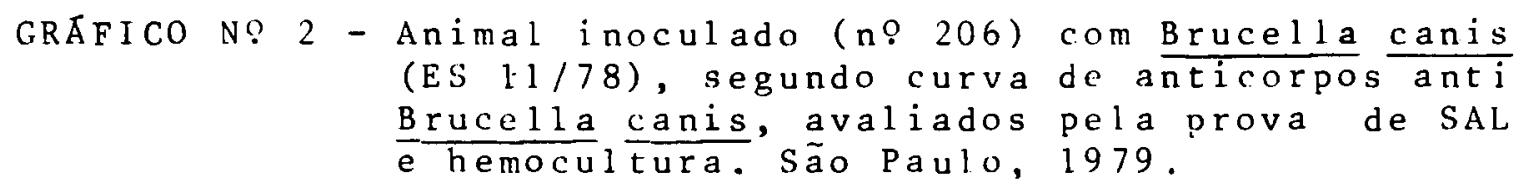

Titulo de

anticorpos

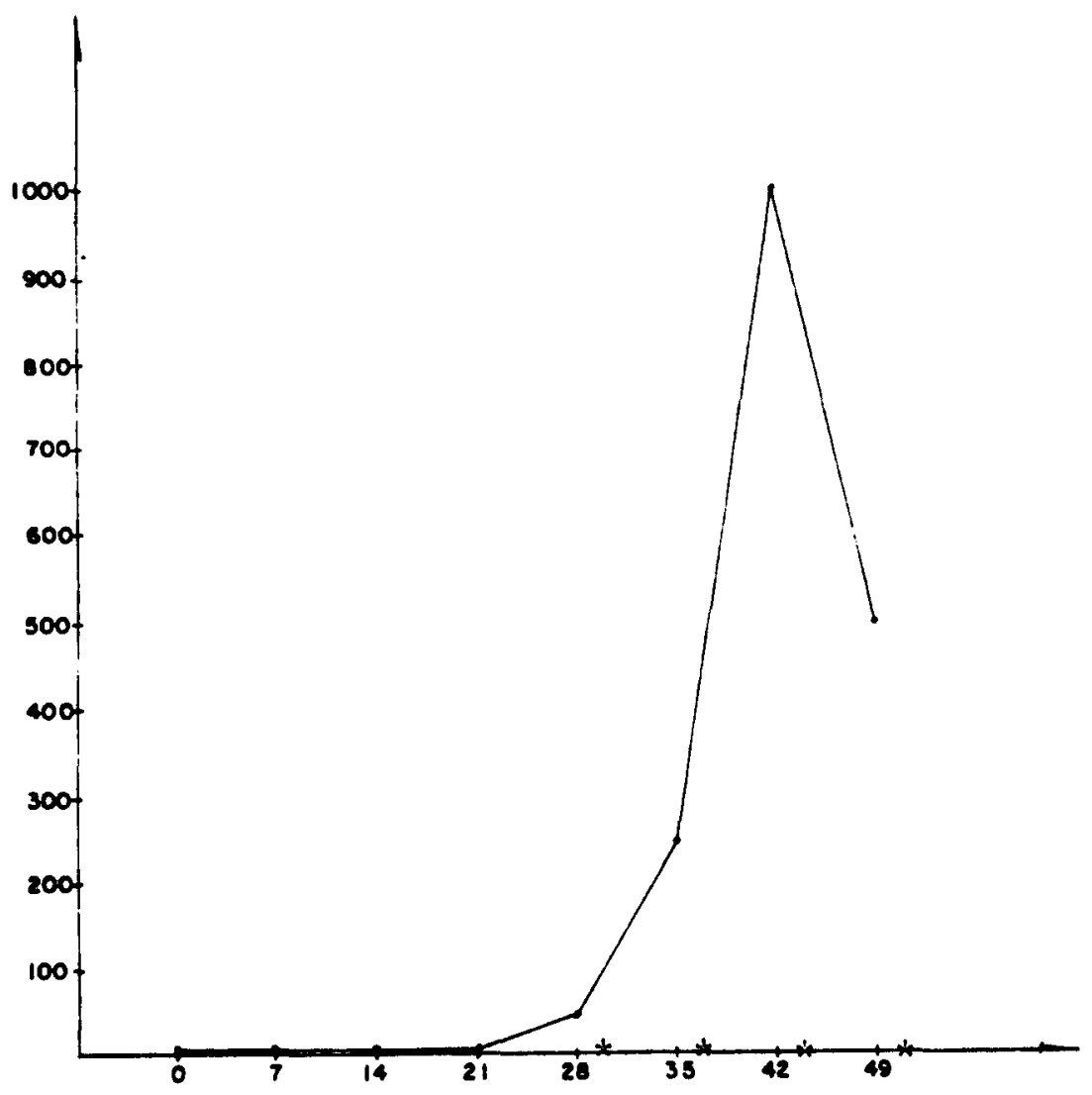

* Hemoçulura positiva.

O animal n? 206 apresentou título inicial positivo igual a 50 no 28 o dia de observação; na coleta seguinte, no 350 dia o título elevou-se para 250, atingindo valor l.000 no 42 ? dia após a inoculação e caindo para 500 no 499 dia de observação.

A Hemocultura positiva foi detectada, inicialmente, no 28 dia de observação e perdurou até o final do experimento (490 dia). 
GRAFICO No 3 - Animal inoculado (no 209) com Brucella canis (ES 1.1/78), segundo curva de anticorpos anti Brucella canis, avaliados pela prova de SAL e hemocultura. São Paulo, 1979.

Titulo de anticorpos

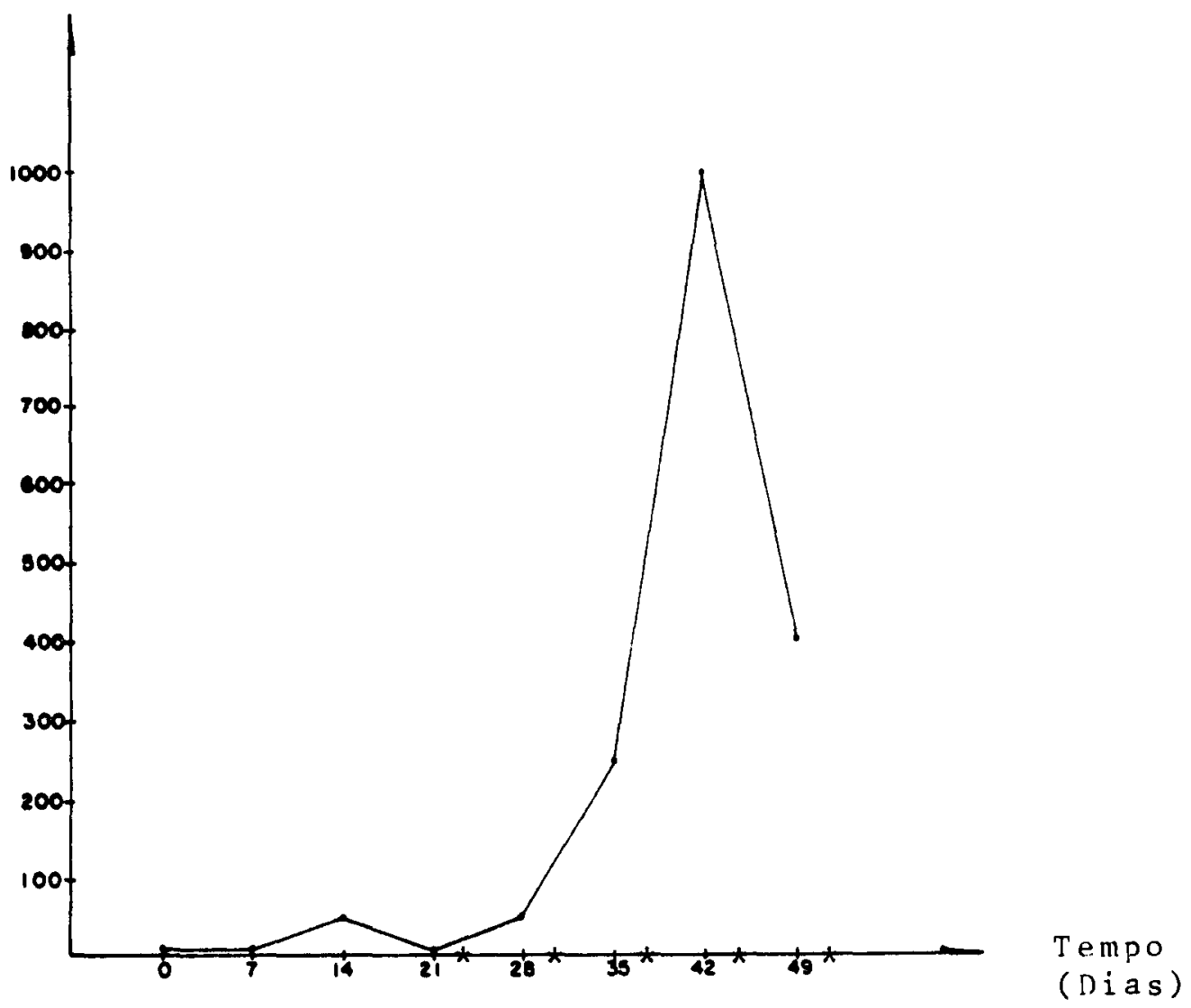

* Hemocultura positiva.

o animal no 209 apresentou título positivo igual a 50 já no 149 dia de observação; na coleta seguinte, no 21 9 dia, apre sentou titulo negativo e no $28 \%$ dia voltou a ser reagente páa ra anticorpos anti Brucella canis, pela prova de SAL. A par tir de então, elevou o titulo para 250 , no 35 a dia, e para 1.000 , no 428 dia de observação; entretanto, na última coleta, realizada no 499 dia após a inoculação, baixou o título para 400 .

A hemocultura positiva neste animal foi detcetada, ini cialmente, no 21 @ dia após a inoculação, assimpermanecendo at - final do período de experimentação. 
$\begin{aligned} \text { GRAFICO No } 4 \text { - } & \text { Animal inoculado (ne 214) com Brucella canis } \\ & \text { (ES } 11 / 78) \text { segundo curva de anticorpos anti } \\ & \frac{\text { Brucella canis, avaliados pela prova de SAL }}{\text { e hemocultura. São Paulo, } 1979 .}\end{aligned}$

Título de.

anticorpos

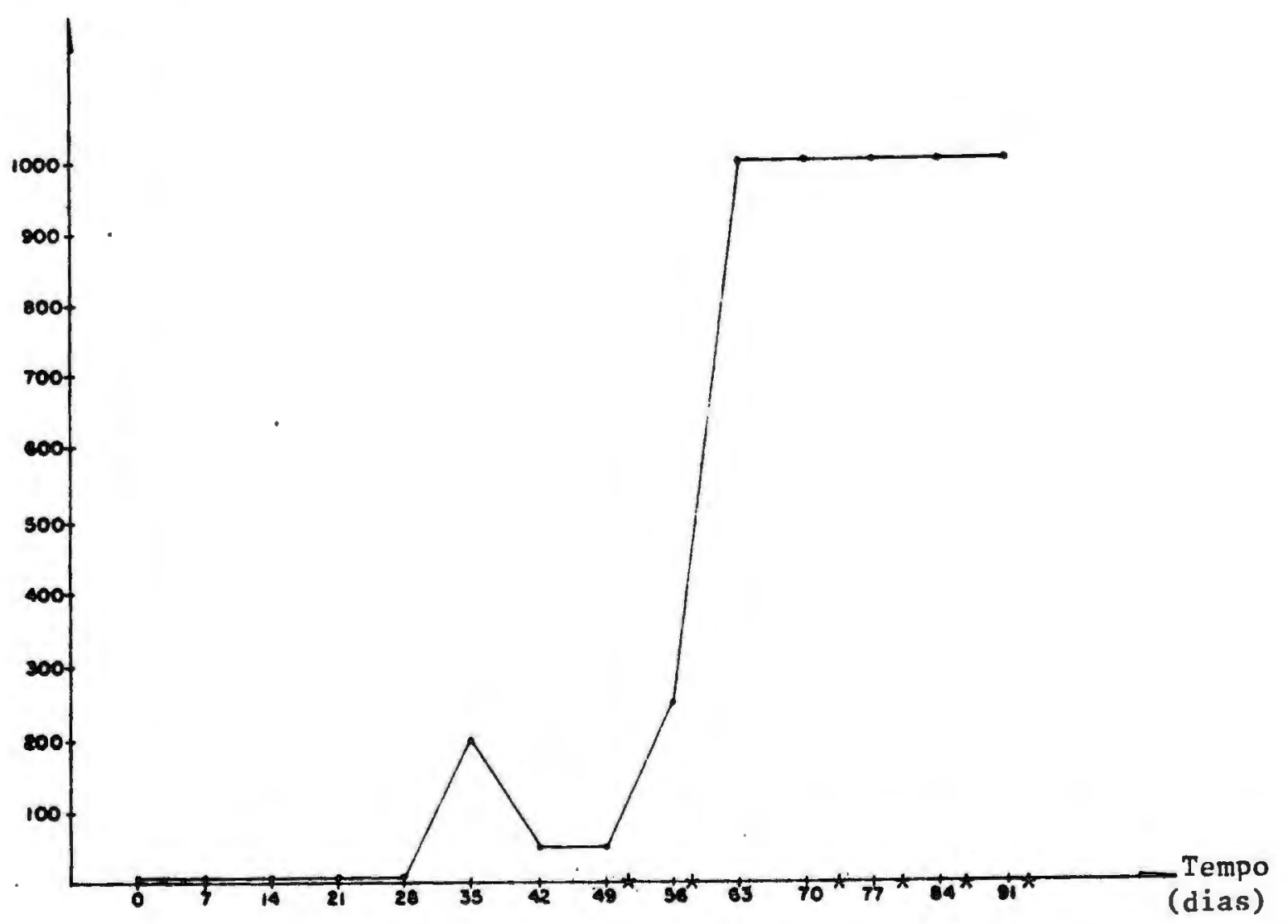

* Hemocultura positiva:

o animal no 214 apresentou, título inicial, relativamen te elevado, iqual a 200 , no 35 o dia após a inoculação, nas duas coletas subsequentes, baixou o nível de anticorpos para 50. No 56 o dia, - título elevou-se para 250, e sete dias após, chegou ao nível 1.000 e assim permaneceu até o final do experimento.

o Gräfico bo 4 permite visualizar que o animal no 214 apresentou hemocultura positiva, pela primeira vez, apenas no 490 dia após a inoculação, ocasião em que era portador de um nível baixo de anticorpos; na coleta seguinte, no $56 \%$ dia, a hemocultura foi novamente positiva, negativando no 630 dia de observação. Nas 4 coletas subsequentes, a hemocultura foi positiva, caracterizando a bacteremia. 
GRAFICO No 5 - Animal inoculado (no 216) com Brucella canis
(ES ll/78), segundo curva de anticorpos anti
Brucella canis, avaliados pela prova de SAL
e hemocultura. São Paulo, 1979.

Título de

anticorpos

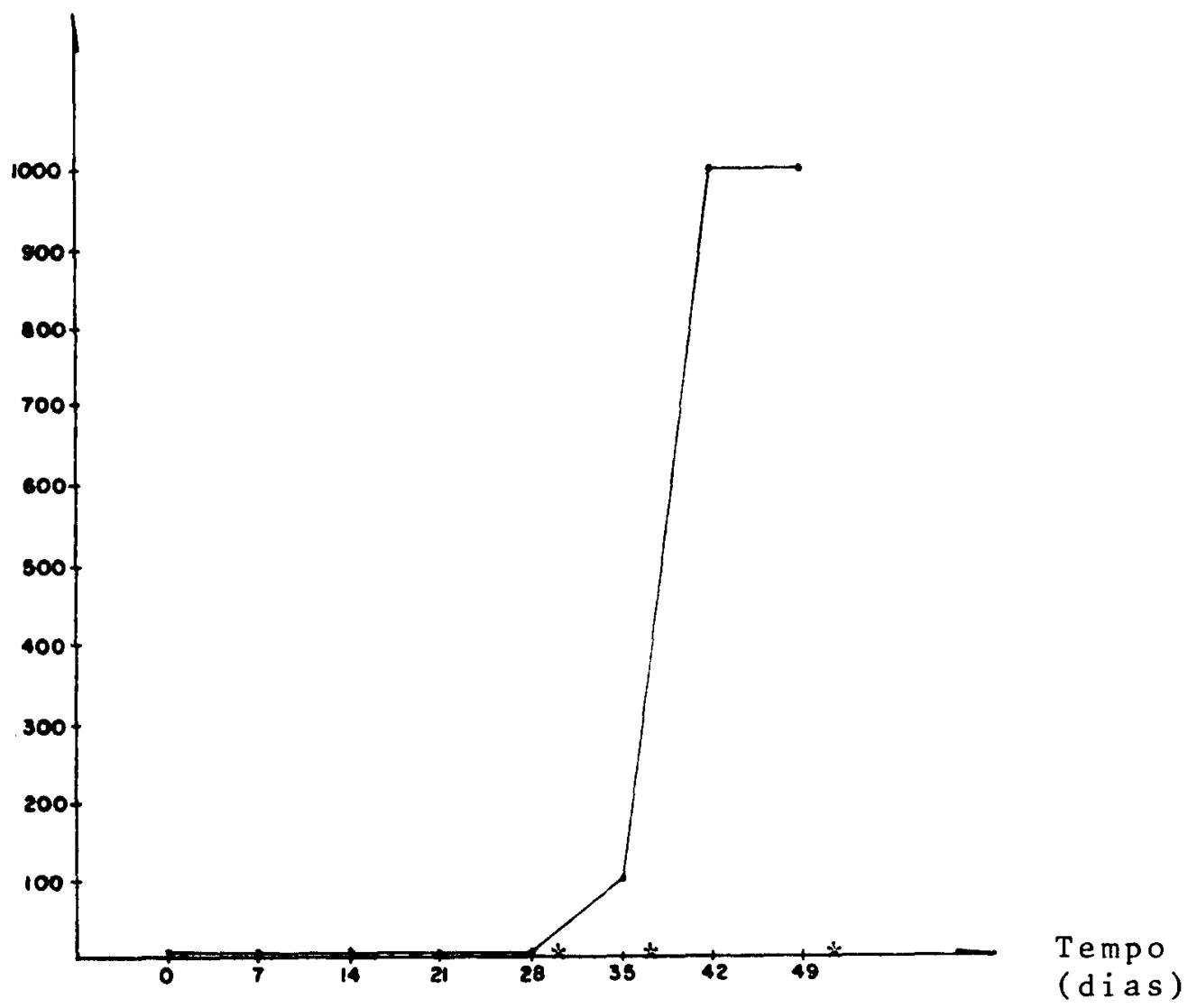

* Hemocultura positiva

o animal no 216 apresentou uma resposta imunológica com título 100 apenas no 35 9 dia após a inoculação; sete dias após, - título havia elevado para 1.000 e se manteve assim até 49 9 dia de observação, ocasião em que o animal foi sacrificado.

A hemocultura positiva foi detectada, pela primeira vez, no 28 Q dia após a inoculação, mesmo na ausência de anticorpos circulantes; foi igualmente observada na coleta seguinte, ne gativando no 429 dia e, positivando, novamente, no 490 dia de observação. 


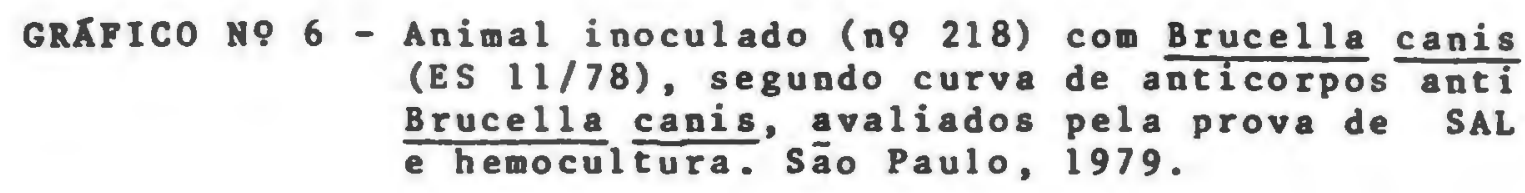

\begin{abstract}
Titulo de
anticorpos
\end{abstract}

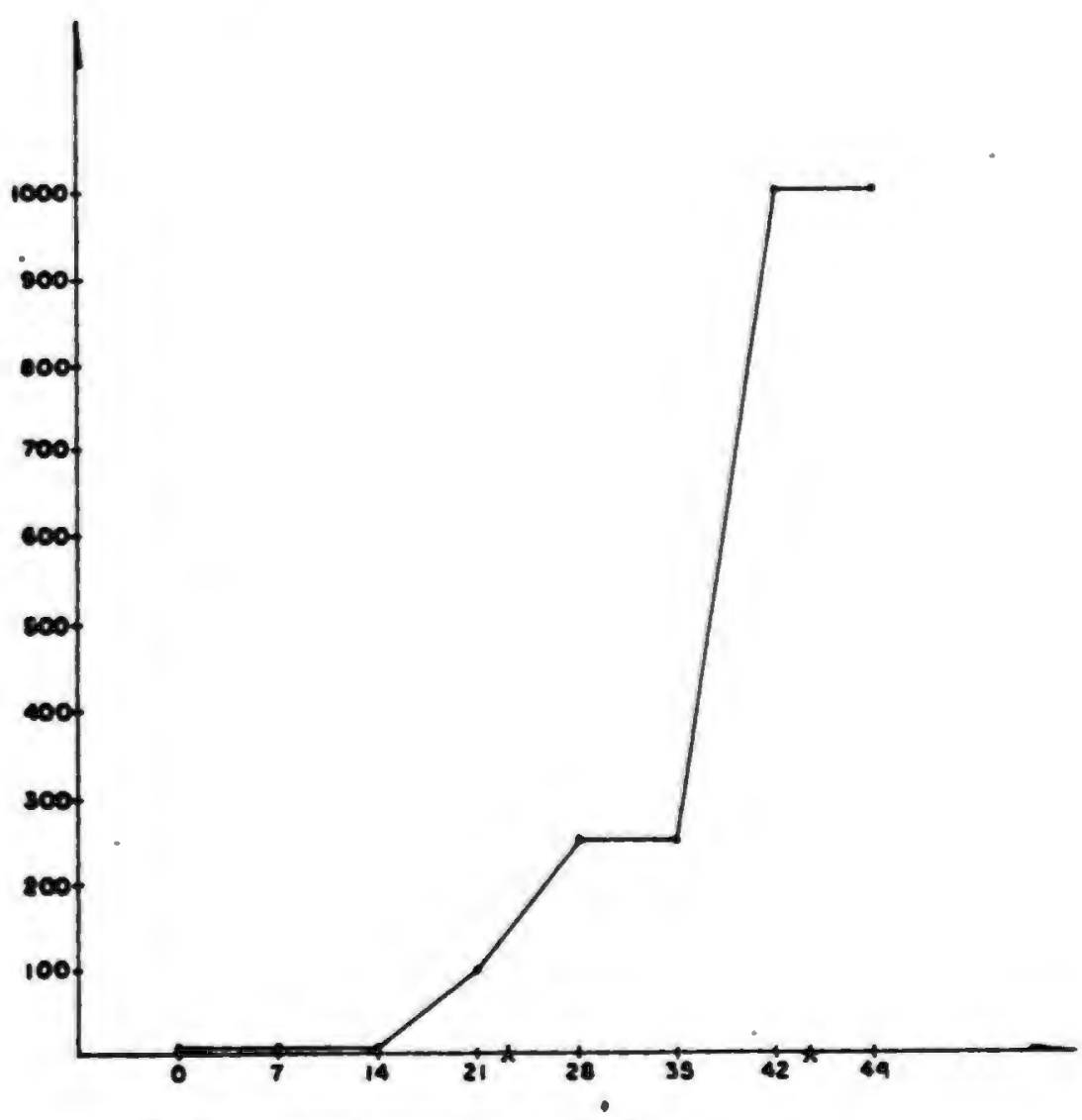

* Hemocultura positiva

O animal ne 218 apresentou titulo inicial a 100 no 218 dia após a inoculação; na coleta seguinte, elevou o título pa ra 250, valor este mantido também no 359 dia de observação.Nas duas coletas subsequantes, o nível de anticorpos foi igual a 1.000 .

Este animal forneceu hemocultura positiva apenas em duas ocasiões, isto é, no 218 dia e 428 dia de experimentação. 
$\begin{aligned} & \text { GRAFICO No } 7- \text { Animal inoculado (no 2l9) com Brucella canis } \\ & \text { (ES ll/78), segundo curva de anticorpos anti } \\ & \text { Brucella canis, avaliados pela prova de SAL } \\ & \text { e hemocul tura. Sa paulo, } 1979 .\end{aligned}$

Título dé

anticorpos

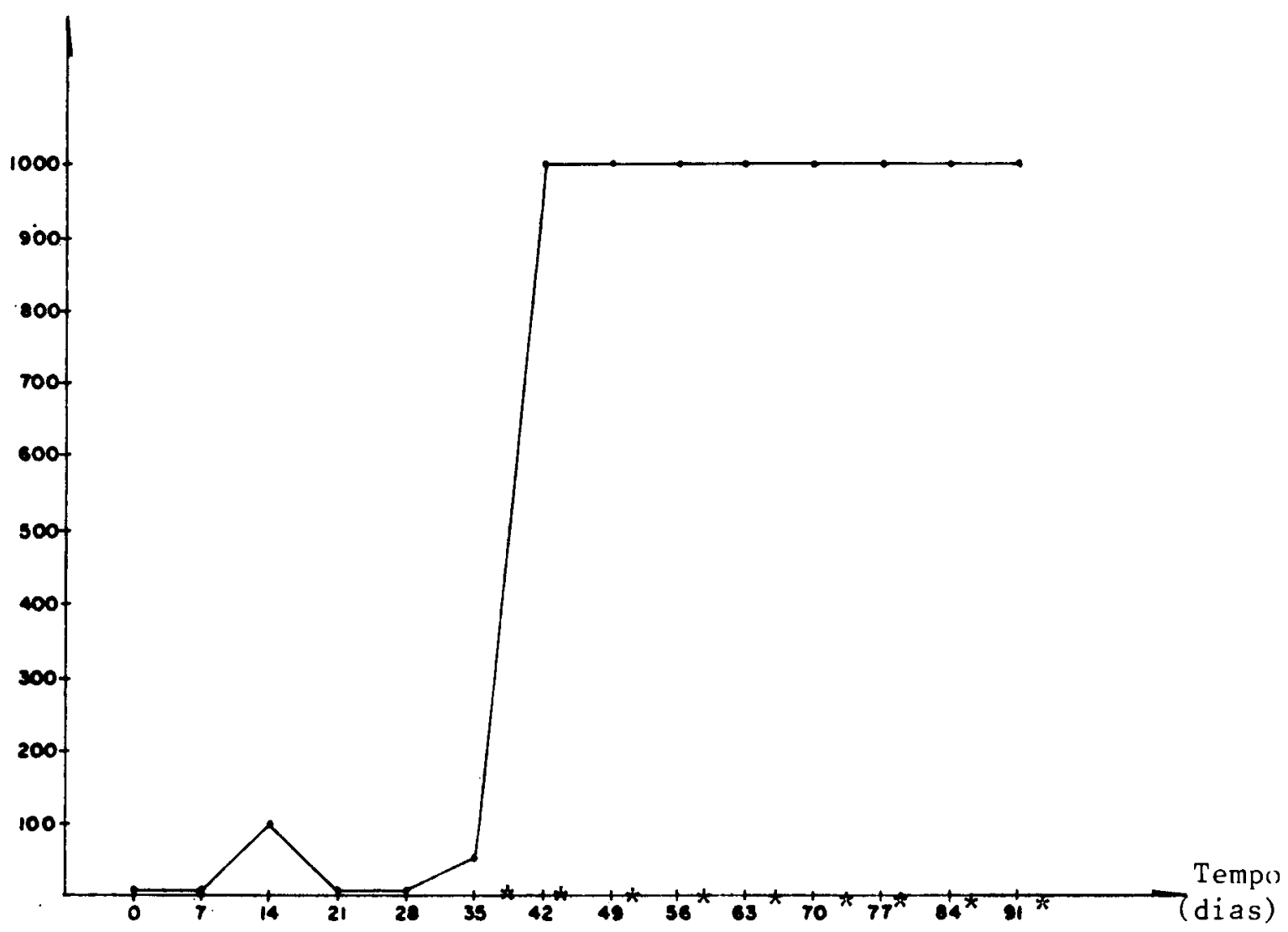

* Hemocultura positiva

0 animal no 219 apresentou uma resposta imunológica preco ce, com título 100 , jä no 14 ọ dia após a inoculação. Nas duas coletas seguintes, não foi possível detectar anticorpos circu lantes e, no 35 9 dia, o nível de anticorpos foi da ordem de $5 \overline{0}$, elevando-se, abruptamente, na coleta seguinte, para 1.000 , va lor que se manteve até o final do experimento.

A hemocultura positiva uma vez detectada, no 350 dia de observação, perdurou até o 919 dia, ocasião em que o animal foi sacrificado. 
TABELA NQ 4 - Animais inoculados com Brucella canis (ES 11/78), segundo titulo aglutinan ce, hemocultura e tempo, em dias, decorrido da inoculaçāo. São Paulo,1979.

\begin{tabular}{|c|c|c|c|c|c|c|c|c|c|c|c|c|c|c|c|c|c|c|c|c|c|c|c|c|c|c|}
\hline Teapo (dias) & \multicolumn{2}{|c|}{7} & \multicolumn{2}{|c|}{14} & \multicolumn{2}{|c|}{21} & \multicolumn{2}{|c|}{28} & \multicolumn{2}{|c|}{35} & \multicolumn{2}{|c|}{42} & \multicolumn{2}{|c|}{49} & \multicolumn{2}{|c|}{56} & \multicolumn{2}{|c|}{63} & \multicolumn{2}{|c|}{70} & \multicolumn{2}{|l|}{77} & \multicolumn{2}{|c|}{84} & \multicolumn{2}{|c|}{96} \\
\hline 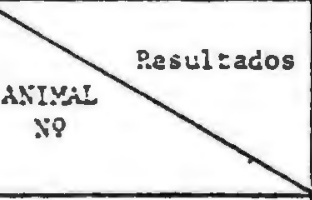 & 章 & 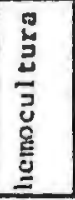 & 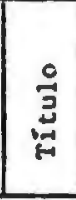 & 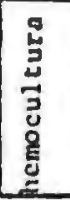 & 苔 & 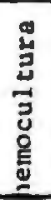 & $\stackrel{\circ}{3}$ & 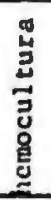 & $\stackrel{\circ}{3}$ & 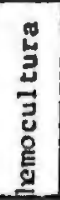 & $\underset{H}{\stackrel{\Xi}{J}}$ & 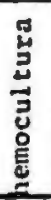 & $\stackrel{0}{3}$ & 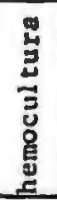 & 总 & 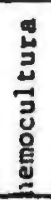 & 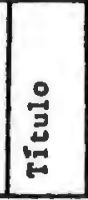 & 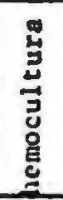 & $\underset{\substack{\mathcal{J} \\
\mathrm{H}}}{\stackrel{0}{3}}$ & 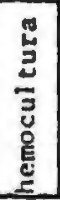 & 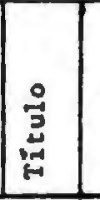 & 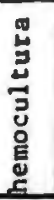 & $\underset{:}{\stackrel{0}{Z}}$ & 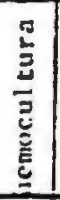 & 굴 & 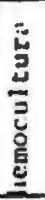 \\
\hline 201 & - & ... & - & $\cdots$ & - & - & - & - & - & - & - & - & - & - & - & - & - & - & - & - & - & - & - & - & - & - \\
\hline 203 & - & $\because$ & - & $\cdots$ & - & - & 50 & + & 100 & - & 500 & + & 1000 & + & 1000 & + & 1000 & + & 1000 & + & 1000 & + & 1000 & +1 & 1000 & + \\
\hline 206 & - & $\cdots$ & - & $\cdots$ & - & - & 50 & + & 250 & + & 2000 & + & 500 & + & $\star$ & & & & & & & & & & & \\
\hline 209 & - & ... & 50 & $\cdots$ & - & + & 50 & + & 250 & + & 1000 & + & 400 & + & * & & & & & & & & & & & \\
\hline 214 & - & ... & - & ... & - & - & - & - & 200 & - & 50 & - & 50 & + & 250 & + & 1000 & - & 1000 & + & 1000 & + & 1000 & & 1000 & + \\
\hline 216 & - & ... & - & ... & - & - & - & + & 100 & + & 1000 & - & 1000 & + & * & & & & & & & & & & & \\
\hline 213 & - & $\ldots$ & - & ... & 100 & + & 250 & - & 250 & - & 1000 & + & 1000 & - & * & & & & & & & & & & & \\
\hline 219 & - & ... & 100 & ... & - & - & - & - & 50 & + & 1000 & + & 2000 & + & 2000 & + & 1000 & + & 1000 & + & 1000 & + & 1000 & + & 1000 & + \\
\hline
\end{tabular}

(*) Animais sacrificados após 49 dias de observaçāo.

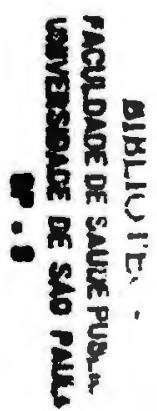


Calculando-se a mediana semanal dos niveis de anticorpos anti Brucella canis de todos os animais inoculados, construiu-se - perfil da curva dos níveis de anticorpos anti Brucella canis, em animais inoculados experimentalmente (Gráfico no 8).

GRAFICO No 8 - Evolução da mediana dos ñiveis de anticorpos anti Brucella canis em cães inoculados expe rimentalmente com Brucella canis (ES $11 / 78$ ), segundo tempo, em dias, descorrido da inocu lação. São Paulo, 1979 .

Título de

anticorpos

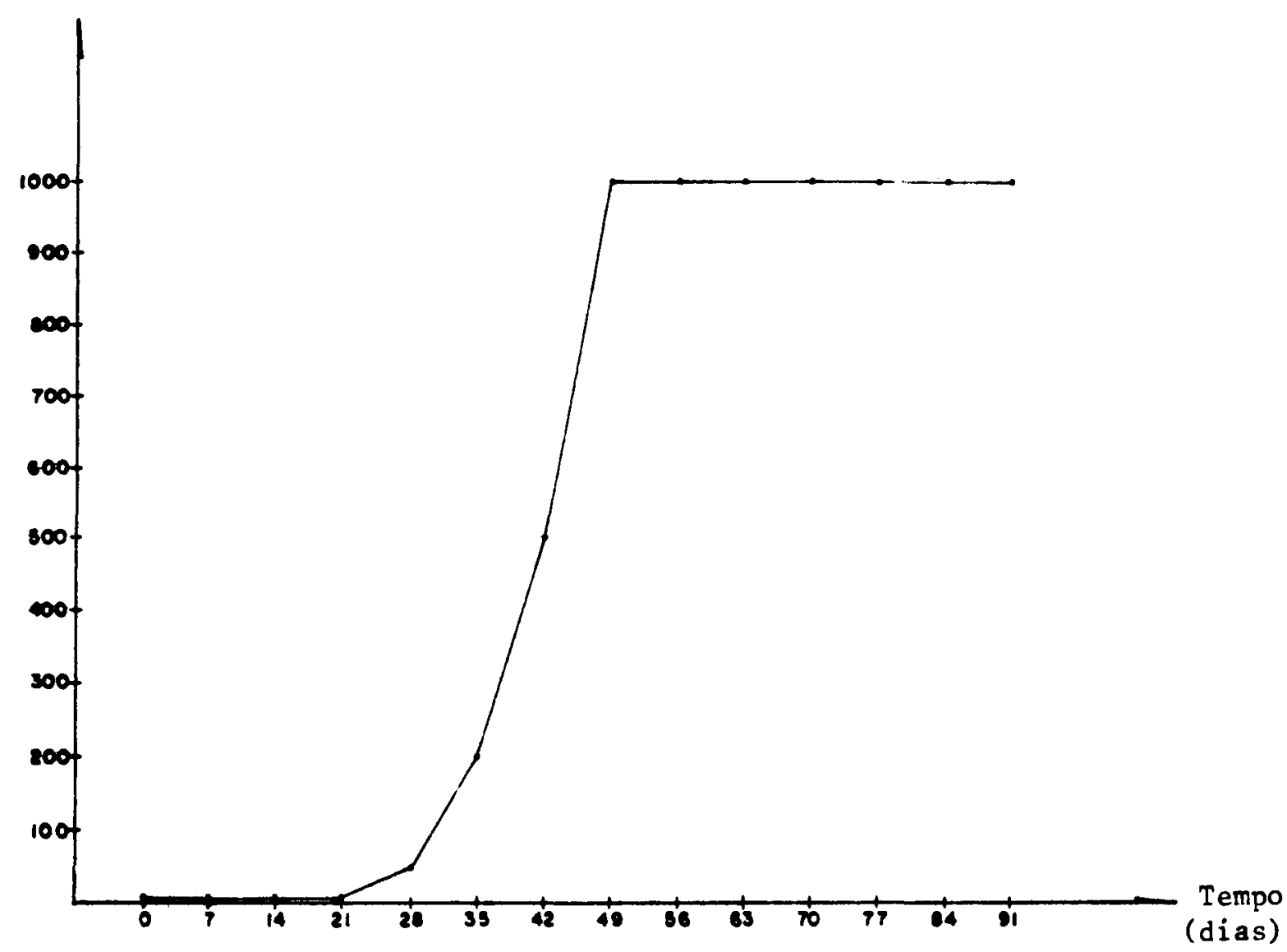


Considerando-se para cada coleta de sangue duas determinações, isto é, prova de SAL e hemocultura, verifi cou-se que 100 é o título que, mais frequentemente, ofere ce hemocultura positiva como sc verifica na TABELA N 5 s que hă uma associação positiva e de intensidade 0.95 , cn tre os fenômenos reagentes para SAL e hemocultura, quando medida pelo coeficiente de associação de Yule (MARASCUIL LO ${ }^{41}$, 1971), conforme se visualiza na TABELA $N^{8} 6$.

TABELA No 5 - Animais inoculados experimentalmente com Bru cella canis (ES 11/78), segundo hemocultura e título aglutinante, avaliado pela prova de SAL. São Paulo, 1979 .

\begin{tabular}{c|c|c}
\hline Hemocultura & Positiva & Negativa \\
\hline Titulo(SAL) & 2 & 18 \\
\hline Negativo & 5 & 1 \\
50 & 2 & 1 \\
100 & - & 1 \\
200 & 3 & 2 \\
250 & 1 & - \\
400 & 2 & - \\
500 & 23 & 3 \\
\hline
\end{tabular}

TABELA NO 6 - Animais inoculados experimentalmente com Bru cella canis (ES 11/78), segundo a prova de SAL e hemocultura. São Paulo, 1979.

\begin{tabular}{c|c|c}
\hline Hemocultura & Positiva & Negativa \\
\hline (SAL) & 36 & 8 \\
reagente & 2 & 18 \\
\hline Tóogente & 38 & 26 \\
\hline
\end{tabular}

Dos oito animais inoculados experimentalmente com Brucella canis (ES 11/78), scte aprescntaram evidencias bac teriológicas e sorológicas da infecção, sendo que anenas um animal, o de $\mathrm{n}^{\circ}$ 201, não desenvolveu título de anticor pos anti Brucella canis, detectáveis pelos métodos soroló 
gicos utilizados no presente trabalho, e tampouco apre sentou hemocultura positiva, durante todo o período de observação de 91 dias. Provavelmente, a quantidade de microrganismos inoculadas neste animal não foi suficien te para que ele se infectasse, ou, ainda, tratava-sc de um animal imune, imunidade esta conferida por uma infec ção anterior, pois organismos intra celulares como a Bru cella geram estado de hipersensibilidade retardada (CAR MICHAEL \& KENNEY 14,1970 ; SYMPOSIUM ON IMMUNITY...67, $1970)$.

PERCY e col. 51 (1972), BROWN e col. 6 (1973). LEWIS JRecol. 39 (1973) e JENNINGS e col. ${ }^{35}$ (1974) de senvolveram tambēm trabalhos de inoculação experimental com Brucella canis em cães, com exceção de PERCY e col. 51 (1972) que trabalharam com símios, conseguindo demons trar evidências sorológicas e bacteriológicas em todos os animais inoculados.

Embora a técnica, relativa à prova de SAL em pregada no presente trabalho, considere reagentes os an $\underline{i}$ mais cujos soros aglutinam em diluição igual ou maior a 1:100, no ítem referente à inoculação experimental, con sideraram-se reagentes os cães inoculados, cujos soros apresentaram aglutinação em diluição menor àquela, pois eles forneceram, simultaneamente, hemocultura positiva. Esta condição foi verificada nos animais de nūmeros 203, 206 e 209 no $28^{\circ}$ dia, no animal n' 214 no $49^{\circ}$ dia e no animal n 219 no $35^{\circ}$ dia após inoculação. Assim, conse guiu-se detectar nível inicial de anticorpos aglutinan tes 14 a 35 dias após a inoculação experimental; resul tados semelhantes foram obtidos por BROWN e col. ${ }^{6}$ (1973), LEWIS JR e col. ${ }^{39}$ (1973), JENNINGS e col. ${ }^{35}$ (1974) e BROWN e col. 5 (1975) que detectaram títulos iniciais, res pectivamente, 4 semanas, 9 a 19 dias, 4 semanas e 14 dias após a exposição dos animais ao agente infectante. As observações acima citadas justifiçam a realização da di luição 1:50, na sequência de diluições de soro na prova de SAL para pesquisa de anticorpos anti Brucella canis, assim como, a realização de hemocultura perante os so ros reagentes em baixas dilui.ções. 
Relativamente à hemocultura, esta foi detecta da inicialmente 21 a 49 dias após a inoculação experimen tal. MOORE 44 (1969), CARMICHAEL \& KENNEY 14 (1970), BROWN e col. 6 (1973), LEWIS JR e col. 39 (1973) e BROWN e col. 5 (1975) detectaram bacteremia inicial, respect vamente, 4 semanas, 1 a 3 semanas, 8 a 23 dias, 0 a 21 dias e 14 dias após a exposição dos suscetíveis ao agente infectante.

Contrariamente às observações de CARMICHAEL \& KENNEY 14 (1970), PERCY e col. 51 (1972) e BROWN e col.6 (1973), detectou-se bacteremia em todos as coletas apenas em 3 animais ( ${ }^{\circ} \mathrm{s} 206,209$ e 219); os demais apresentaram resultados irregulares em relação à hemocultura, à seme 1hança do que verificaram VAN HOOSIER JR. e col. 72 (1970), em 2 récém-nascidos, que nasceram de mãe infectada, e a presentaram hemocultura positiva no $3^{\circ}$ dia de vida e hemo cultura negativa nas coletas subsequantes.

Os resultados obtidos no presente trabalho são concordes com os de MOORE \& GUPTA $4 \hat{6}$ (1970)no que diz res peito à verificação dos níveis mais elevados de anticor pos circulantes em animais bacterémicos; entretanto, as afirmações dos mesmos autores da não ocorrência de título 800 sem bacteremia, não foram observadas no presente tra balho, pois de 35 resultados de SAL com títulos iguais ou maiores a 200 , título este indicativo de infecção ati va, 29 forneceram hemocultura positiva e 6 foram negati vos para cultura de sangue (TABELA N:5).

Segundo CARMICHAEL \& KENNEY ${ }^{14}$ (1970), a Bru cella canis pode ser isolada do sangue (porção leucocitáa ria) poucos dias antes do aparecimento de níveis detectá veis de anticorpos aglutinantes; de forma anāloga, obte ve-se, no presente trabalho, hemocultura positiva de 2 a nimais que não apresentavam aglutininas anti Brucella ca nis detectáveis pela prova de SAL (animal n $\mathrm{n}^{\circ} 209$ no $21^{\circ}$ dia após a inoculação e animal $n^{\circ} 216$ no $28^{\circ}$ dia após a inoculação, conforme TABELA Nं 4). 
4.4. Infecção por Brucella canis em humanos.

Dos trezentos e trinta soros humanos examina dos pela prova de SAL, encontraram-se quatro positivos para Brucella canis, dando uma prevalência de $1,21:$.

Dentre os trabalhos relativos à prevalência de aglutininas anti Brucella canis em soros humanos, po dem-se citar os de: HOFF \& SCHNEIDER ${ }^{34}$ (1975) que encon traram $3(0,99 \%)$ reagentes de um total de 303 amostras examinadas;LEWIS JR \& ANDERSON 38 (1973) que, examinando 1208 soros de recrutas militares americanos, através da prova de SAL, encontraram uma porcentagem de soroposi tividade de 0,41 ; FLORES-CASTRO \& SEGURA 20 (1976) que, dentre 203 soros humanos examinados, observaram 27 , ou seja, 13,3\%, positivos; BARG e col. 2 (1977) que obser varam uma prevalência de $0,81 \%$ de reagentes para antí corpos anti Brucella canis de um total de 2020 soros hu manos (doadores de sangue), através das provas de SAR e SAL; WEBER \& BRUNER 77 (1977) que, dentre 1915 soros hu manos, detectaram anticorpos aglutinantes contra Bru cella canis em 6 amostras $(0,31 \%)$, através do teste de SAL.

o resultado obtido, no presente trabalho, rela tivo à prevalência de anticorpos anti Brucella canis em soros humanos $(1,21 \%)$, pela prova de SAL, é concorde com os dos autores acima citados, com exceção do de FLO RES-CASTRO \& SEGURA 20 (1976).

Constam da literatura médica,vārios trabalhos referentes a relatos de casos humanos de doença por Bru cella canis. CARMICHAEL e col. 15 (1968) foram os pri meiros a descrever a infecção no homem, em 2 laborato ristas, que se infectaram acidentalmente, trabalhando com amostras de Brucella canis. SWENSON e col. ${ }^{66}$ (1972), descreveram o primeiro caso humano de infecção por Bru

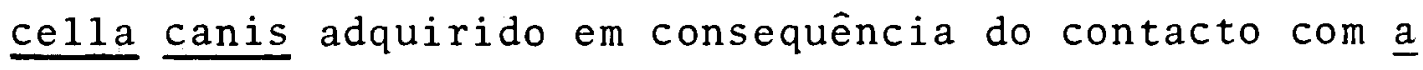


nimal doente. O paciente envolvido tratava-se de uma mulher de 23 anos de idade, portadora de doença cardía ca reumática, que apresentava febre, tremores e faring te. Sua hemocultura foi positiva para Brucella canis e seu título aglutinante igual a 200. Ntravés de inves tigação epidemiológica, incriminou-se um animal da es pécie canina, fêmea, com hemocultura positiva, como sen do a fonte de infecção; os demais elementos da família eram todos negativos para hemocultura e presença de an ticorpos aglutinantes. MUNFORD e col. 48 (1975) rela taram outros 2 casos humanos de infecção por Brucella canis em indivíduos não envolvidos, profissionalmente, ao risco dá infecção e que apresentaram sintomas tais como febre, arrepios, indisposição e perda de peso; em ambos os casos a provảvel fonte de infecção foi o an mal de estimação. BLANCKENSHIP \& SANDFORD ${ }^{4}$ (1975) in criminaram uma cadela de" 2 anos de idade, com título a glutinante de 200 , como fonte de infecção de mais um caso humano de doença por Brucella canis, envolvendo um homem de 48 anos de idade, com os seguintes sintomas: fe bre intermitente e bacteremia de 4 meses de duração. Ao exame clínico detectaram-se ainda: linfadenopatia, hēpa to e esplenomegalias e sinais de processo infeccioso a gudo. O paciente em questão apresentava título aglutí nante contra Brucella canis igual a 500 e hemocultura positiva. Os demais elementos da familia foram todos negativos à diluição de 1:50 para pesquisa de anticor pos anti Brucella canis. LOVEJOY e col. 40 (1976) des creveram, no Tenessi, outro caso de infecção humana por Brucella canis em um jovem de 18 anos de idade que ad quiriu a doença através do contacto com seu animal de estimação que, na ocasião, era portador de altos niveis de anticorpos circulantes.

Assim sendo, segundo CENTER FOR DISEASE CON TROL 16 (1977), existem relatados na literatura médica, no período de 1967-1974, 16 casos humanos de infecção. por Brucella canis. Em 11 deles, o diagnóstico foi ba seado no isolamento do agente; 5 deles foram diagností 
cados sorologicamente por testes de aglutinação especí fica para Brucella canis, sendo que 2 deles foram con firmados por testes subsequentes com elevação do título, e nos 3 restantes fêz-se diaṇnóstico presuntivo com bạ se em título único e estävel igual ou maior a 100. Scis dos 16 casos ocorreram em laboratoristas; seis outros adquiriram a infecção por contacto com cães infectados; nos 4 casos restantes, a fonte de infecção foi desconhe cida. Os casos acima descritos associados ao fato de que as infecções ativas, por Brucella canis em cães, po dem persistir por värios meses (WOOLEY e col., ${ }^{83}, 1976$ ) fazem crer que o homem pode, realmente, se infectar com o agente do aborto canino.

Assim sendo, deve-se pensar na possibilidade de infecção humana por Brucella canis em casos de febre e linfadenopatia de etiologias indeterminadas. 
5. CONCLUSOES. 
5. CONCLUSOES.

Os resultados obtidos através da metodologia cmpre gada permitiram chegar às conclusões descritas a seguir.

5.1. A prevalência da infecção nos animais de canil, segundo a prova de SAR, foi igual a $9,1 \%$, a passo que se ohservou $2,4 \%$ de reagentes segundo a prova de SAL. No atinente aos cães errantes, observou-se uma prevalência de $7,5 \%$ de so ropositivos, segundo a prova de SAR, e 7\% segundo a pró va de SAL.

5.2. De seis animais reagentes examinados por meio de hemocul tura, foram isoladas três amostras de Brucella canis, re velando que $50 \%$ dos cães soropositivos apresentavam-se bac terêmicos por ocasião da coleta de sangue.

5.3. As aglutininas anti Brucella canis foram detectadas, pela primeira vez, entre o $14^{\circ}$ e $35^{\circ}$ dias após a inoculação ex perimental por via oral, enquanto que a hemocultura posi tiva foi observada, pela primeira vez,21 a 49 dias após a exposiçãodos animais ao agente infectante.

5.4. Houve uma associação, positiva entre reagente para anticor pos anti Brucella canis e hemocultura positiva.

5.5. A prevalência da infecção humana por Brucella canis, ava liada através da pesquisa de aglutininas específicas, foi realizada pela primeira vez em São Paulo, encontrando-se resultado igual a $1,21 \%$. 
6. REFERENCIAS BIBIIIOGRAFICAS. 
6. REFERENCIAS BIBLIOGRAFICAS. *

1. ALTON, G. G.; JONES, L. M. \& PJETZ, D. G. Las tecnicas de la boratorios en la brucelosis. Cincbra, Organizacion Mundial de la Salud, 1976. (Série de monografias, 55).

2. BARG, L.; GODOY, A. M. \& PERES, F. N. Pesquisa de aglutininas anti Brucella canis em soros humanos. Arq. Esc. Vet. U F M G, 29: $31-4,1977$.

3. BLAIR, J. E.; LENNET, E. H. \& TRUANT, J. P. Manual of clinicid microbiology. American Society of Microbiology. Betheseda, Williams \& Williams Co., 1970.

4. BLANKENSHIP, R. M. \& SANDFORD, J. P. Brucella canis: a case of undulant fever. Amer. J. Med., 59: 424-6, 1975 .

5. BROWN, G. M.; PIETZ, D. E. \& RANGER, C. R. Experimental Brucel

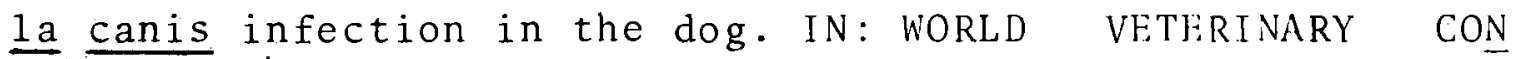
GRESS, 20 th , Thessaloniki, 1975. Proccedings.Thessaloniki, 1975. v. 2, p. 785-6.

6. BROWN, G. M.; PIETZ, D. E. E RANGER, C. R. Serologic and bac teriologic procedures for the diagnosis of Brucella canis. Proc. U.S. anim. H1th Ass., 77: 532, 1973 .

7. BROWN, J.; BLUE, J. L.; WOOLEY, R. E. E DRELSEN, D.W. Brucella canis infectivity rates in stray and pet dogs ponulations. Amer. J. pub1. H]th, 66: 889-91, 1976 .

8. BROWN, J.; BLUE, J. L.; WOOLEY, R. E.; DREESEN, D. W. \& CARMI CHAEL, L. E. A scrologic survey of a population of Gcorgia dogs for $B$. canis and an evaluation of slide agglutination test. J. Amer. vet. med. Ass., 169: 1214-6, 1970 .

(*) DE ACORDO COM:

ASSOCIAÇÃO PAULISTA DE BIBLIOTECĀRIOS. Grupo de Bibliotecá rios Biomédicos. Referências bibliográficas em ciências bín médicas. São Paulo, 1971 
9. CARMICHAEL, L. E. Canine bruce 11 osis: an annoted review with selected cautionary comments. Theriogenology, $\underline{6}$ : 105-16, 1976 .

10. CARMICHALL, L. L. Canine hrucellosis: isolation, diagnosis, transmission. Proc. U.S. Livestock Sanit. Ass., 71: 51.7$-27,1969$.

11. CARMICHAEL, I.. E. Contagious abortion in beagles. Hounds and Hunting. 64: 14-8, 1967.

12. CARMICHAEL, L. E. \& BRUNER, D. W. Characteristics of a new $1 y^{-}$ - recognized species of Brucella responsible for infectious canine abortions. Corne11 vet., 58: 579-92, 1968.

13. CARMICHAEL, L. E. \& GEORGE, L. W. Canine brucellosis: newer knowledge. International symposium on brucellosis (II), Ra bat, 1975 . Develop. bio1. Stand., 31: 237-50, 1976 .

14. CARMICHAEL, L. E. \& KENNEY, R. M. Canine brucellosis: the clinical disease, pathogenesis, and immune response. J. Amer. vet. med. Ass., 156: 1726-34, 1970 .

15. CARMiCHAEL, L. E.; BAROL, S. R.; BROAD, R. H. \& FREITAG, J. L. Human infection with the agent of canine abortion.Bol.inf. trimest. Centro Panamer. Zoon., 10: 24-7, 1968 .

16. CENTER FOR DISEASE CONTROL. Brucellosis in the United States, 1965-1974. J. infect. Dis., 136: 312-6, 1977 .

17. CLEGG, F. G. Brucel1a abortus infection in the dog. A case of polyarthritis. Res.vet. Sci., 9 : 183-5, 1968 .

18. DAMP, S. C.; CRUMRINE, M. H. \& LEWIS JR., G. E. Microtiter pla te agglutination test for Brucella canis antibodies.Appl. Microbiol., 25: $489-90,1973$.

19. FAIGEL, H. C. Beagle fever-canine brucellosis. Clin.Pediatr., 8: 59,1969 . 
20. FLORES-CASTRO, R. E SEGURA, R. A serological and bacteriolog cal survey of canine brucellosis in Mexico. Cornell vet., 66: $347-52,1976$.

21. FREDRICKSON, L. E. \& BARTON, C. E. A serologic survey for ca nine brucellosis in a metropolitan area. J.Amer. vet.med. Ass., 165: 987-9, 1974 .

22. FREEMAN, A. Canine brucel1osis. J.. Amer. vet. med. Ass., 159: $6-7,1971$.

23. GALPHIN JR., S.P. A serologic survey for Brucella canis in dogs on a military base. J. Amer. vet. med. Ass., 171: 728$-9,1977$.

24. GEORGE, L. W. \& CARMICHAEL, L. E. A plate agglutination test for the rapid diagnosis of canine brucellosis. Amer. J. vet. Res., 35: 905-9, 1974 .

25. GEORGE, L. W. E CARMICHAEL, L. E. Development of a rose ben gal stained plate-test antigen for the rapid diagnosis of Bruce11a canis infection. Corne11 vet., 68: 530-43, 1978 .

26. GLEiser, C. A.; SHELDOM, W. G.; VAN HOOSIER JR., G. L. \& HILL, W. A. Pathologic changes in dogs infected with a Brucella organism. Lab. anim. Sci., 21: 540-5, 1971 .

27. GODOY, A. M.; PERES, J. N. \& BARG, L. Isolamento de Brucella canis em Minas Gerais, Brasil. Arq. Esc. Vet. UFMG, 29: 35-42, 1977.

28. HALL, W. H. Epidemic brucellos is in beagles. J. infect. Dis., 124: $615-8,1971$.

29. HARRIS, A. M.; HORTON, M. L.; LETSCHER, R. M.; MC CONNELL, E. E. \& NEW, A. L. Brucella canis - an occult disease in a research canine colony. Lab. anim. Sci., 24: 796-9, 1974. 
30. HAYASHI, T.T. A. \& ISAYAMA;: Y. Detection of Brucella canis in fection in dogs in Hokkaido. Microbiol. Immunol., 21: 295$-8,1977$.

31. HENDERSON, R. A.; HORLEIN, B. I: ; KRAMER, T. T. i MI:YLR, M.li. Discospondylitis in three dogs infẹcted with Brucella ca nis. J. Amer. vet. med. Ass., 165: 451-5, 1974 .

32. HILl, W. A.; VAN HOOSIER JR.,.G. L. \& McCORMICK, N. Enzootic abortion in a canine production colony I. Epizootiology. clinical features and control procedures $1,2,3$. Lab. anim. Care, 20: 205-8, 1970 .

33. HOFF, G. L. \& NICHOLS, J. B. Canine brucellosis in Florida:se rologic survey of pounds dogs, animal shelter workers and veterinarians : Amer. J. Epidem., 100: 35-9, 1974.

34. HOFF, G. L. \& SCHNEIDER, N. J. Serologic survey for aggluti nins to Bruceila canis in Florida residents. Amer. J.trop. Med. Hyg, 24: 157-9, 1975 .

35. JENNINGS, ’P. B. CRUMRINE, M. H. ; LEWIS JR., G. E. \& FARISS, B. L. The effect of a two-stage antibiotic regimen on dogs infected with Brucella canis. J.Amer. vet. med. Ass., 164: $513-4, .1974$.

36. KIMBERLING, C. V.; LUCHSINGER, D. W: \& ANDERSON, R. K. Three cases of canine brucellosis. J.Amer. vet. med. Ass. 148: $900-1,1966$.

37. LEWIS JR., G. E. A serological survey of 650 dogs to detect titers for B. canis ( B. suis, type 5). J.Amer.anim.Hosp. Ass., $\underline{8}$ : $102-7,1972$.

38. LEWIS JR:, G. E. \& ANDERSON, J. K. The incidence of Brucella canis antibodies in sera of military recruits. Amer. J. pub1. H1th, 63: 204-5, 1973 . 
39. LEWIS JR., G. E.; CRUMRINE, M. H.; JENNINGS, P. B. E FARISS, B.L. Therapeutic value of tetracycline and ampicillin in dogs infected with Brucella canis. J. Amer.vet. med.Ass., $\underline{163}: 239-41,197.3$.

40. LOVEJOY, G. S.; CARVER, H. D.; MOSELEY, I. K. \& HICHS, M.Se ro survey of dogs for Brucella canis infection in Memphis, Ten nessee. Amer. J. pub1. H1th, 66: 175-6, 1976.

41. MARASCUILLO, L. A. Statistical methods for behavioral science research. New York, McGraw Hil1, 1971.

42. MCCORMICK, N.; HILL, W. A.; VAN HOOSIER JR. G.L. \& WENDE, R. Enzootic aburtion in a canine production colony. II. Cha racteristics of the associated organism, evidence for its classification as B. canis, and antibody studies on expos cd humans. Lab. anim. Care, 20: 209-14, 1970 .

43. MEYER, M. E. Advances in research on brucellosis, 1957-1972. Adv. vet. Sci. comp. Med., 18:231-50, 1974 .

44. MOORE, J. A. Bruce11a canis infection in dogs. J. Amer. vet. med. Ass., 155: 2034-7, 1969 .

45. MOORE, J. A. \& BENNETT, M. A previously undescribed orga nism associated with canine abortion. Vet. Rec., 80:604 $-5,1967$.

40. MOORE, J. A. \& GUPTA, B. N. Epizootiology, diagnosis, and con trol of Brucel1a canis. J.Amer. vet. med. Ass., 156:1757 $-40,1970$.

47. MOORE, J. A. \& KAKUK, T. J. Male dogs naturally infected with Bruce11a canis. J. Amer. vet. med. Ass. 155: 1352-8,1969.

48. MUNFORD, R. S.; WEAVER, R. E.; PATTON, C.; FIELEY, J. C. \& FELDMAN, R. A. Human disease caused by Brucella canis. $\Lambda$ clinical and epidemiologic study of two cases. J. Amer. med.Ass., 231: 1267-9, 1975. 
49. MYERS, D. M. ;VARELA-DIAZ, V. M. \& COLTORTI, E. A. Comparat $\underline{\mathbf{i}}$ ve sensitivity of gel-diffusion and tube agglutination tests for the detection of Brucella canis antibodies in experi mentally infected dogs. Appl. Microbiol. 28: 1-4, 1974 .

50. NICHOLLETTI, P. L; QUINN, B. R. \& MINOR, P. W. Canine to human transmission of brucellosis. N.Y.St. J.Med.. 67: 2886$-7,1967$.

51. PERCY, D. H.; EGWU, I. N. \& JONAS, A. M. Experimental Brucel 1 a canis infection in the monkey (Macaca arctoides) Canad. J.comp Med., 36: 221-5, 1972 .

52. PEREIRA FILHO, M.; SILVA, J. A. H. da \& ROCHA, J. V. N. da.E tudo da incidência da brucelose canina na zona metropolita na de Salvador. In: CONGRESSO BRASILEIRO DE MEDICINA VETE RINARlA, Salvador, 1978. Anais. Salvador, BA., $1978 . p .32$.

53. PHILLIPON, A.; ROUMY, B. \& RENOUX, G. Un cas de brucellose canine à Bruce 1la abortus. Bull. Acad. vët. France, 42: 923-8,1969.

54. PICKERILL, P. A. Comments on epizootiology and control of ca nine brucellosis. J. Amer. vet. med. Ass., 156: 1741-2, 1970 .

55. PICKERILL, P. A. \& CARMPCHAEL, L. E. Canine brucellosis: con trol programs in commercial kennels and effect on reproduc tion. J.Amer. vet. med. Ass., 160: 1607-15, 1972 .

56. RIECKE, J. A. \& RHOADES, H. E. Brucella çanis isolated from the eye of a dog. J.Amer. vet. med. Ass., 166: 583-4,1975.

57. ROBERTSON, M. C. Brucella infection transmitted by dog bite. J. Amer. med. Ass., 225: 750-1, 1973 .

58. SAEGUSA, J.; UEDA, K.; GOTO, Y. \& FUJIWARA, K. Ocular lesions in experimental canino brucellosis. Jap. J. vet. Sci., 39: $181-5,1977$. 
59. SANDOVAL, L. A.; RIBEIRO, L. O. C.; AMARAL, L. B. S.;FEITOSA, M. H. \& BAZAN, J. M. Incidência da brucelose canina na cidade de São Paulo. Biológico, 42: 128-32, 1976.

60. SCHOEB, T. R. \& MORTON, R. M. Scrotal and testicular changes in canine brucellosis: a case report. J.Amer. vet. med. Ass., 172: 598-600, 1978 .

61. S̆EBEK, Z.; SYKORA, I.; HOLDA, J. \& KOMAREK, J. Sérologickȳ pr $\underline{8}$ kaz Brucella canis $v$ chovu laboratorních psů plemene bea gle v Čskoslovensku. Es. Epidem., 25: 129-36, 1976.

62. SERIKAWA, T.; MURAGUCHI, T. \& NAKAO, N. Significance of uri ne culture for detecting infection with Brucella canis in dogs. Jap. J. vet. Sci., 40: 353-5, 1978.

63. SERIKAWA, T.; MURAGUCHI, T. \& NAKAO, N. A survey of dogs from Gifu and Shiga area for Brucella canis. Jap. J. vet. Sci.. 39: $635-42,1977$.

64. SPINK, W. W. Comments on canine brucellosis due to Brucella canis. J.Amer. vet. med. Ass., 156:1734-6, 1970 .

65. SPINK, W. W. \& MORISSET, R. Epidemic canine brucellos is due to a new species: B. canis. Trans. Amer. clin. Climatol.Ass., 81: $43-50,1970$.

66. SWENSON, R. M.; CARMICHAEL, L. E. \& CUNDY, K. R. Human infec tion with Brucella canis. Ann. intern. Med., 76: 435-8, 1972 .

67. SYMPOSIUM ON IMMUNITY TO SELECTED CANINE INFECTIOUS DISEASES, New York, 1969. Report of the panel. J.Amer. vet. med. Ass., 156: 1661-8, 1970 .

68. TAUL, L. K.; POWELL, H. S. ¿ BAKER, O. E. Canine abortion due to an unclassified Gram-negative bacterium. Vet. Med.small Anim. C1in., 62: 543-4, 1967. 
69. TERAKADO, N.; UEDA, H.; SUGAWARA, H.; ISAYAMA, Y. \& KOYAMA, N. Drug suscetibility of Brucella canis isolated from dogs. Jap. J. vet. Sci., 40 : 291-5, 1978 .

70. UEDA, K..; MAGARIBUCHI, T.; SAEGUSA, J.; IJRAN(), l.; I'luH. K.; KIUCHI, Y. \& FUJIWARA, K. Spontaneous Bruce11a canis in fection in beagles: bacteriological and serological stu dies. Jap. J. vet. Sci., 36: $381-9,1974$.

71. UEDA, K.; SAEGUSA, J.; FUJIWARA, K.; MUTO, S. ; OKADA, K. ; HA SEGAWA, A.; SAEGUSA, S. E USUI, K. Detection of Brucella canis infection in dogs from Tokyo area. Jap. J. vet. Sci.. 36: $539-42,1974$.

72. VAN HOOSIER.JR., G. L.; MCCORMICK, N. G HILL, W. A. Enzootic abortion in a canine colony. III. Bacteremia, antibody res ponse and mercaptoethanol sensitivity of agglutinins in na tura11y infected dogs ${ }^{1,2,3}$. Lab. anim. Care. 201:904-8. 1970 .

73. VERGER, J. M.; GATtÉ, M.; PIECHAUd, M.; ChATElain, R.; RAMISSE, J. \& BLANCOU, J. Isolement de Brucella suis biotype 5 à Madagascar chez une chienne. Validité du nom d'espèce Bru cella canis. Ann. Microbiol., Paris, 126 (A): 57-74,1975.

74. VON KRUEDENER, R. B. Isolierung und Bestimmung von Brucella canis aus einem Beaglebestand. Zbl. Vet.-Med., 21 B: $507-$ $-10,1974$.

75. VON KRUEDENER, R. B. Outbreak of a Brucella canis infection in a beagle colony in West Germany. International symposium on brucellosis (II), Rabat, 1975. Develop. biol. Stand., 31 : $251-3,1976$.

76. WEBER, A. [Distribution of Brucel1a canis infection in hea gles in the German Federal Republic]. Fortsch. Vet. Med.. 25: 272-8, 1976 apud Vet. Bu11. 4 46:6388, 1976. 
77. WEBER, A. \& BRUNER, H. Seroepidemiologisch untersuchungen zum Vorkommeen von Antikörpern gegen Brucella canis bein Mens chen. Zb1. Bakt. Hyg. I. Abt. Orig. A 238: 237-43, 1977.

78. WEBER, A. E IIUSSEIN, N. $\Lambda$. Der indirckte I mmunlluoreszenztest zum Nachweis von Brucella canis Infektionen bei Beagle-Hun dun. Zb1. Vet.-Med., 23 B: 151-7, 1976.

79. WEBER, A. \& KRAUSS, H. Über die Branchbar eit des Agargel Prä zipitationtestes zum Nackwies von Brucella canis - Infek tionen bei Beagle - Hunden . Berl. Munch. tierarztl.Wschr.. 88: $425-7,1975$.

80. WEBER, A. \& SCHLIESSER, T. Serologischer und kultureller Nach weis von Brucella canis bei Beagle - Hunden einer Versuchs tierhaltung. Zb1. Vet.-Med., 22 B: 403-10, 1975 .

81. WEBER, A. \& SCHLIESSER, T. Untersuchungen zum Vorkommen von Antikörpern gegen Brucella canis bei Haushunden in der Bun desrepublik Deustschland. Berl. Munch. tierärztl. Wschr., 91: $28-30,1978$.

82. WEBER, A. \& SCHULZ, H. P. Über den Nachweis von Brucella ca nis bei Beagle - Hunden. Kleintierpraxis, 21: 23-8, 1970.

83. WOOLEY, R. E.; BROWN, J. E RLUE, J. L. Canine Brkellosis in man. Mod. vet. Pract., 57: 287-90, 1976.

84. WOOLEY, R. E.; BROWN, J.; SHOTTS, E. B.; BLUE, J. L. E DREFSEN, D. W. Serosurvey of Brucella canis antibodies in urban an rural stray dogs in Georgia. Vet. Med. small Anim. Clin.. 72: $1581-4,1977$.

85. YAMAUCHI, C.; SUZUK1, T. \& NOMURA. T. Canine brucellosis in a beagle breeding colony. Jap. J. vet. Sci., 36: 175-82, 1974 . 